\title{
Nalbantlar Ovası (Söke, Aydın) Yeraltı Suyu ve Tarım Toprakları İnorganik Kalite Araştırması: Arsenik ve Uranyum Tehlikesi
}

\author{
Inorganic Quality Study of Groundwater and Agricultural Soils on Nalbantlar Plain \\ (Söke, Aydın): Arsenic and Uranium Hazard \\ Anıl KÜÇÜKSÜMBÜL ${ }^{1}$ D, Gültekin TARCAN ${ }^{1}$ (D) \\ ${ }^{1}$ Dokuz Eylül Üniversitesi, Mühendislik Fakültesi, Jeoloji Mühendisliği Bölümü, 35390 İzmir
}

\section{ÖZ}

Bu çalışma, Batı Anadolu'da Aydın iline bağlı Söke Ovası doğusunda yer alan ovalarda tarım toprağı ve yeraltı suyu kalitelerinin incelenmesi ile insan sağlığı üzerindeki etkisinin araştırılmasını kapsamaktadır. İnceleme alanı ve çevresindeki jeolojik yapının temelini Menderes Masifi kayaçları oluşturmaktadır. Bölgede yüzeylenen gnays, granitoyid ve şist metamorfik kayaçları; su ve toprakların kimyasını belirleyen önemli parametrelerdir. Suların içme amaçlı tüketiminde; çözünmüş $\mathrm{As}, \mathrm{B}, \mathrm{Ba}, \mathrm{Cd}, \mathrm{Cr}, \mathrm{Cu}, \mathrm{Ni}, \mathrm{Pb}, \mathrm{U}$ ve $\mathrm{Zn}$ değerlerinin kanserojen olan/olmayan toplam sağlık riski hesaplanmıştır. Yeraltı sularının kirlenmesine neden olan antropojenik ve jeojenik girdiler ayırt edilmiştir. Ek olarak, sularda majör iyonlar $\left(\mathrm{Ca}, \mathrm{Mg}, \mathrm{K}, \mathrm{Na}, \mathrm{Cl}, \mathrm{SO}_{4}, \mathrm{HCO}_{3}\right)$ ve birçok eser element $(\mathrm{Ag}, \mathrm{Al}, \mathrm{Co}$, $\mathrm{Fe}, \mathrm{Ge}, \mathrm{Mn}, \mathrm{Pd}, \mathrm{Rb}, \mathrm{Se}, \mathrm{Si}, \mathrm{Sr}, \mathrm{Ta}, \mathrm{Tl}$ ve V) analiz edilmiştir. Tarım topraklarının $\mathrm{As}, \mathrm{Cd}, \mathrm{Co}, \mathrm{Cr}, \mathrm{Cu}, \mathrm{Hg}, \mathrm{Ni}, \mathrm{Pb}$, $\mathrm{Sb}, \mathrm{U}$ ve Zn değerleri analiz edilmiştir. Söke Ovası topraklarının elementçe zenginleşme faktörleri hesaplanarak temel değerler ile karşılaştırılmışıı. Toprakların solunması, yutulması ve deriyle teması yoluyla oluşan kanserojen olan/olmayan toplam sağlık riski hesaplanmıştır. Bazı yeraltı suları gnays biriminden kaynaklı olduğu belirlenen, ortalamanın çok üzerinde çözünmüş uranyum ve arsenik içermektedir. Ovada, yeraltı suyu kuyularının derinliği arttıkça çözünmüş uranyum miktarında artış söz konusudur. Sınır değerinin $(30 \mu \mathrm{g} / \mathrm{L}) 3$ katı kadar uranyum içeren yeraltı suyu, Karacahayıt bölgesinde içme amaçlı tüketilmektedir. Yeşilköy, Karacahayıt ve Kisir mahallerinde yasal sınırın üzerinde (sırasıyla 23.1, 24.1 ve $61.1 \mu \mathrm{g} / \mathrm{L}$ ) arsenik içeren yeraltı suyu, içme amaçlı tüketilmektedir. İçme amaçlı tüketilen yeraltı sularında en yüksek kanser riski arsenik için 2.07E-03 olarak Kisir bölgesinde belirlenmiştir. Tarım topraklarında en yüksek kanser riski arsenik için 2.38E-04 olarak Sayrakçı bölgesinde belirlenmiştir. Sağlık açısından riskli olan suları tüketen ve topraklarda tarım etkinliğinde bulunan yöre halkının sağlık durumu araştırılmalı ve çözüm önerileri uygulanmalıdır.

Anahtar Kelimeler: İnsan Sağlığı Risk Değerlendirmesi, Su Kimyası, Su Kirliliği, Kanser, Toprak Kirliliği, Yeraltı suyu

\section{ABSTRACT}

This study includes the investigation of the quality of agricultural soils and groundwater in the plains located in the east of Söke Plain in Aydin province in Western Anatolia and the detection of its effect on human health. The rocks belonging to the Menderes Massifform the basis of the geological structure in the study area and surrounding. Metamorphic rocks composed of gneiss, granitoid and rocks outcropping in the region are essential parameters 
Küçüksümbül, Tarcan

determining the water and soils' chemistry. The total carcinogenic and non-carcinogenic health risk values of waters were calculated for dissolved $\mathrm{As}, \mathrm{B}, \mathrm{Ba}, \mathrm{Cd}, \mathrm{Cr}, \mathrm{Cu}, \mathrm{Ni}, \mathrm{Pb}, \mathrm{U}$ and $\mathrm{Zn}$. Anthropogenic and geogenic inputs that cause groundwater contamination were distinguished. Also, major ions ( $\mathrm{Ca}, \mathrm{Mg}, \mathrm{K}, \mathrm{Na}, \mathrm{Cl}, \mathrm{SO}_{4}, \mathrm{HCO}_{3}$ ) and many trace elements ( $\mathrm{Ag}, \mathrm{Al}, \mathrm{Co}, \mathrm{Fe}, \mathrm{Ge}, \mathrm{Mn}, \mathrm{Pd}, \mathrm{Rb}, \mathrm{Se}, \mathrm{Si}, \mathrm{Sr}, \mathrm{Ta}, \mathrm{Tl}$ and $\mathrm{V}$ ) were analyzed. Collected soil samples were analyzed for $\mathrm{As}, \mathrm{Cd}, \mathrm{Co}, \mathrm{Cr}, \mathrm{Cu}, \mathrm{Hg}, \mathrm{Ni}, \mathrm{Pb}, \mathrm{Sb}, \mathrm{U}$ and $\mathrm{Zn}$. The elemental enrichment factors of Söke Plain soils were calculated and compared with the background values. Carcinogenic and non-carcinogenic total health risks, which is occurred by inhalation, ingestion and dermal contact of soil, were calculated. Some groundwater contains above-average dissolved uranium and arsenic, which are determined to originate from the gneiss unit. In the plain, the abundance of dissolved uranium increases as the depth of groundwater wells rises. Groundwater containing uranium 3 times the limit value $(30 \mu \mathrm{g} / \mathrm{L})$ is consumed for drinking purposes in the Karacahaylt region. Groundwater containing arsenic above the allowed limit in Yeşilköy, Karacahaylt and Kisir regions (23.1, 24.1 and $61.1 \mu \mathrm{g} / \mathrm{L}$, respectively) is consumed for drinking purposes. The highest cancer risk for As in groundwater consumed for drinking was found to be 2.07E-03 in Kisir. The highest cancer risk for As in agricultural soil was found to be 2.38E-04 in Sayrakçl. The local people health status who work on soil with health risks and consume carcinogenic waters should be investigated, and suggestions for the solution should be implemented.

Keywords: Human Health Risk Assessment, Water Chemistry, Water Contamination, Cancer, Soil Contamination, Groundwater

\section{GíRiș}

İçme, sulama ve/veya hayvancilık amaciyla kullanılan yüzey ve yeraltı suları ile tarımsal faaliyette kullanılan toprağın korunması insanlığın hayatta kalması için vazgeçilmezdir. Jeojenik ve antropojenik girdiler nedeniyle su ve toprakta, kimyasal elementlerin birikimi gerçekleşmektedir. Jeolojik süreçler engellenemese bile olası etkisinin araştırılması, halk sağlığ1 ve sürdürülebilir kaynak yönetimi için gerekliliktir.

Çalışma alanı Söke - Koçarlı Ovası 2. Kısım olarak anılan Azap Gölü kuzeydoğusundaki Nalbantlar Ovasi, Karacahayıt bölgesi ve güneydoğusundaki Yeşilköy Ovası'nı kapsamaktadır (Şekil 1). Küçüksümbül vd. (2022) tarafından Söke Ovası su ve topraklarının kimyasal analiz sonuçları değerlendirilmiştir. Azap Gölü ve çevresinde gnays biriminden kaynaklı jeojenik kirlenme rapor edilmiştir. Söke Ovası'nın su ve topraklarını kapsayan çalışmanın ardından jeojenik kirlenme beklenen yerleşkelere odaklanılmıştır. İçme, sulama, hayvancılık amaçlı kullanılan yeraltı suları ve tarım yapılan topraklardan örneklemeler yapılmıştır. Söke Ovası'ndan farklı biçimde Büyük Menderes Nehri (BMN) sularından bağımsız olarak Kisir Çayı ve yağışlı dönem dereleri ile beslenen ovalarda, birçok noktada üretim sağlanan yeraltı suyu kuyuları bulunmaktadır. Kisir, Sayrakçı, Nalbantlar, Karacahayıt, Çalıköy ve Yeşilköy bölgesindeki örneklemeler üzerinden su ve toprak kalitesi araştırılmıştır. Jeolojik etki göz önünde bulundurularak yeraltı suyu ve tarım topraklarının inorganik madde bolluğunun nedenleri ve insan sağlığına uygunluğu değerlendirilmiştir.

\section{YÖNTEM VE MATERYAL}

Yerleşim bölgelerinden 9 adet su ve 8 adet toprak örneklemesi yapılmıştır. Su ve toprak örnek noktaları literatürden alınanlarla birlikte Şekil 1 ve 2'de gösterilmiştir. Taze formasyon suyu örneklemeleri, kuyularda 15 dakika süren su çekimi ardından yapılmıştır. Elektriksel iletkenlik, $\mathrm{pH}$ ve sıcaklık değerleri arazide multimetre aracılığıyla ölçülmüştür. Tüm su örnekleri, yüksek yoğunluklu polietilen şişelere örneklenmiş olup $4{ }^{\circ} \mathrm{C}$ 'de korunmuştur. 


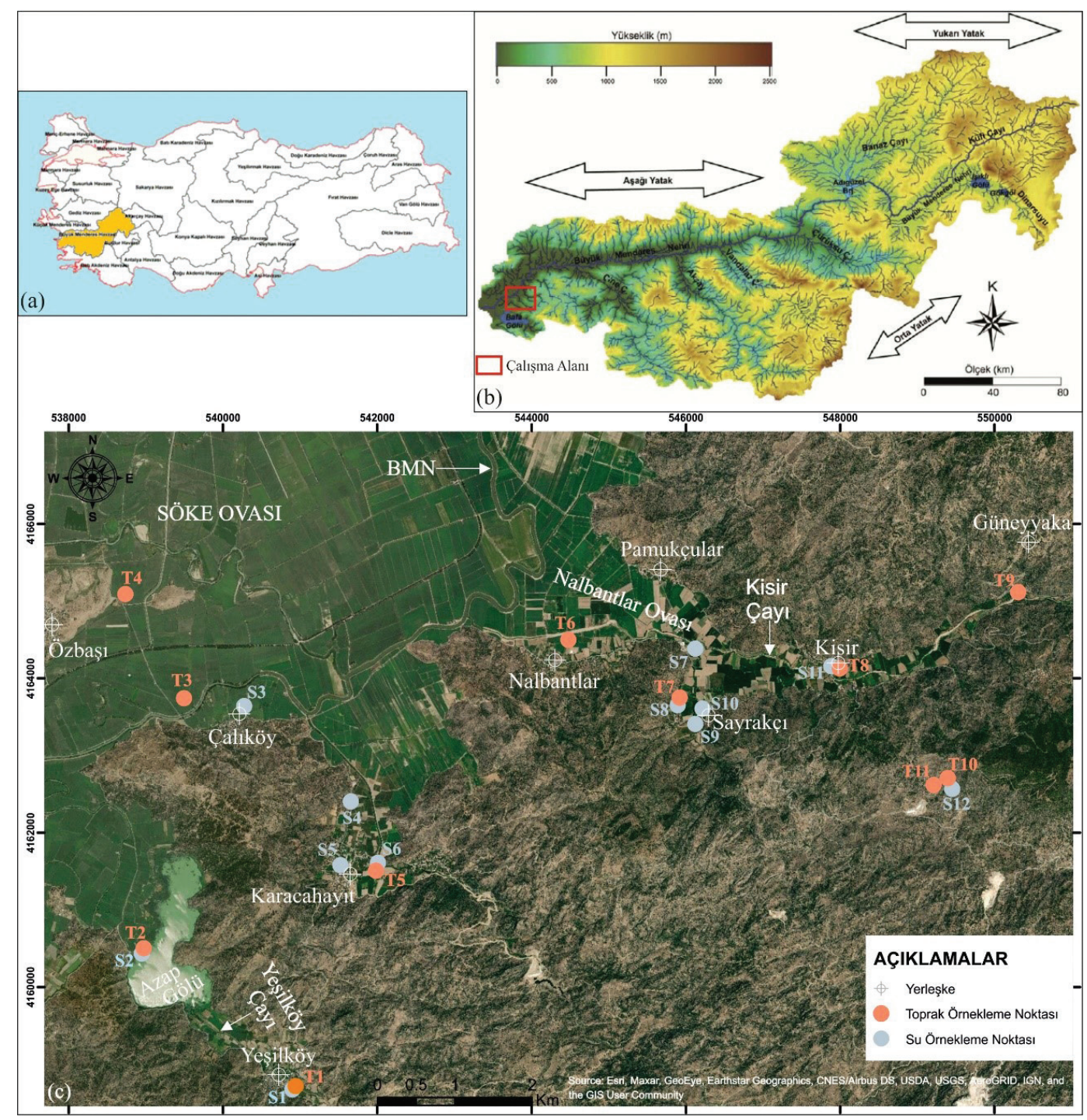

Şekil 1. (a) Büyük Menderes Havzası'nın konumu, (b) Büyük Menderes Havzası ve çalışma alanının havzadaki konumu (Kazancı vd., 2011), (c) Çalışma alanının uydu görüntüsü ve örnekleme noktalarının yeri.

Figure 1. (a) Location of Büyük Menderes Basin, (b) Büyük Menderes Basin and location of the study area in the Basin, (c) Satellite image of the study area and location of the sampling points.

Majör katyon $\left(\mathrm{Na}^{+}, \mathrm{Mg}^{+2}, \mathrm{Ca}^{+2}, \mathrm{~K}^{+}\right)$analizleri Dokuz Eylül Üniversitesi Jeoloji Mühendisliği Bölümü Jeokimya Laboratuvarında Atomik Absorpsiyon Spektrofotometresi cihazında gerçekleştirilmiştir. Majör anyon $\left(\mathrm{Cl}^{-}, \mathrm{HCO}_{3}^{-}\right.$, $\mathrm{SO}_{4}^{-2}$ ) analizi için volümetrik ve gravimetrik analiz yöntemleri uygulanmıştır. S1, S6, S8, $\mathrm{S} 10$ ve $\mathrm{S} 12$ örneklerinin anyon analizlerinde teknik sorunlar yaşanmıştır. İz element analizleri için $0.45 \mu \mathrm{m}$ selüloz filtreler kullanılmış ve örnekler $\mathrm{pH}$ değeri 2'ye düşürülene kadar $\mathrm{HNO}_{3}$ eklenerek asidik hale getirilmiştir. 
Küçüksümbül, Tarcan

As, Ag, Al, B, Ba, Cd, Cr, Cu, Co, Fe, Mn, $\mathrm{Ni}, \mathrm{Pb}, \mathrm{Pd}, \mathrm{Rb}, \mathrm{Se}, \mathrm{Si}, \mathrm{Sr}, \mathrm{Ta}, \mathrm{Tl}, \mathrm{U}, \mathrm{V}$ ve $\mathrm{Zn}$ analizleri ICP-MS aracılığıla S5, S7, S9 ve S11 suları için Hacettepe Üniversitesi Su Kimyası Laboratuvar1'nda; S1, S6, S8, S10 ve S12 sular1 için ODTÜ Kimyasal Analiz Laboratuvarı'nda gerçekleştirilmiştir. Ortalama ölçüm hatası $\mathrm{mg} / \mathrm{L}(\mathrm{ppm})$ düzeyindeki derişimler için okunan değerin \% $\%$ 'i, $\mu \mathrm{g} / \mathrm{L}(\mathrm{ppb})$ düzeyindeki derişimler için okunan değerin \%10'u dolayındadır. S2 Azap Gölü ve S13 Büyük Menderes Nehri yüzey suyu örneklemeleri Küçüksümbül vd. (2020)'den, S3 Çalıköy ve S4 Karacahayıt yeraltı suları analizleri Küçüksümbül vd. (2022)'den alınmıştır. S13, Büyük Menderes Nehri'nin Söke Ovası havza girişinden örneklenmiştir. Çalışma alanının yaklaşık $10 \mathrm{~km}$ kadar kuzeyinde yer almaktadır. Bu nedenle, yer bulduru ve jeoloji haritasında işaretlenmemiştir. Tarım yapılan topraklarda yüzey kirlenmesi giderildikten sonra (5-15 cm), 8 adet örnekleme yapılmıştır. Metal donanım kullanımından kaçınılmıştır. $80{ }^{\circ} \mathrm{C}$ 'de kurutulan örnekler, Dokuz Eylül Üniversitesi Jeokimya Laboratuvarında saklanmıştır. Toprakların kimyasal içerikleri, Kanada ACME Laboratuvarı'nda ICP-MS kullanılarak belirlenmiştir. Toprak kimyasında As, Cd, Co, $\mathrm{Cr}, \mathrm{Cu}, \mathrm{Hg}, \mathrm{Ni}, \mathrm{Sb}, \mathrm{Pb}, \mathrm{U}$ ve $\mathrm{Zn}$ elementlerine odaklanılmıştır. T2 Azap Gölü sedimanı, T3 Çalıköy ve T4 Özbaşı toprak analizleri Küçüksümbül vd. (2022)'den alınmıştır.

\section{Jeoloji, Hidrokimya, Jeokimya}

Çalışma alanı Menderes Masifi içerisinde Söke Grabeni'nin doğu kanadında yer almaktadır. Çalışma alanındaki, en yaşlı kayaç Prekambriyen yaşlı gnayslardır. Gnays birimindeki kuvars damarı ve gnaysa geçişteki kuvarsitlerde aynı yönlü çatlaklarda ikincil uranyum minerallerinin yerleştiği rapor edilmiştir (Öztunall, 1965). Kisir-Osmankuyu sahasında \%0.02-0.03 tenörlü 11.530 ton $\mathrm{U}_{3} \mathrm{O}_{8}, \% 0.03$ 'den büyük tenörlü
34.365 ton $\mathrm{U}_{3} \mathrm{O}_{8}$ olmak üzere toplam 45.895 ton muhtemel rezerv rapor edilmiştir (Güney ve Akgül, 2019). Üst Paleozoyik-Prekambriyen yaşlı granitoyid ve Paleozoyik yaşlı şişt birimi gnaysları üstlemektedir (Şekil 2). Gnays, granitoyid ve şişt birimleri dokanaklar hariç geçirimsiz olma özelliği gösterirler. Bazı tektonik kökenli çatlaklarda yağışı dönemde yağmur sularının düşük debide yüzeylendiği gözlenmiştir. Kuvaterner yaşlı alüvyon ise drenaj ağındaki kayaçlar ve dere sedimanları ile beslenmektedir. Alüvyon birimi yüksek geçirimlidir. Söke Ovası'nın aksine birçok sığ ve derin kuyudan yeraltı suyu üretimi yapılmaktadır. Bu sular içme, sulama ve hayvancılık gibi farklı amaçlarla değerlendirilmektedir.

\section{Örnekleme Bilgileri ve Analiz Sonuçları}

T1 toprağ 1 granitoyid biriminde yer alan alüvyon üzerine kurulu Yeşilköy yerleşkesinin tarım toprağını temsil etmektedir. Aynı bölgede içme ve sulama amaçlı kullanılan 12 metre derinliğindeki S1 kuyu suyu örneklenmiştir. T2 göl sedimanı ve S2 su örneklemesi Azap Gölü'nün kimyasal karakterini yansitmaktadır. T3 ve T4 toprakları Büyük Menderes Nehri ile sulanan topraklardır. S3 kuyusu 18 metre derinliğinde olup Çalıköy bölgesinde içme amaçlı tüketilen yeraltı suyudur. Büyük Menderes Nehriyle (S13) beslenmesi olas1 yeraltı suyudur. S4, S5 ve S6 kuyu suyu örnekleri ise Karacahayıt bölgesinden alınmıştır. S4 ve S6 kuyuları yaklaşık 10 metre derinliğindedir ve içme amaçlı yeraltı suyu üretimi yapılmaktadır. S5 kuyusu 45 metre derinlikte olup içme, sulama ve hayvanc1lık amaçlı tüketilmektedir. S4 ve S5 yeraltı suları alüvyon-gnays birimi dokanağında yer almaktayken, S6 örneklemesi doğrudan bölgedeki alüvyon akiferini temsil etmektedir. T5 toprağı Karacahayıt bölgesi tarım arazilerini temsil eden toprak örneklemesidir. 


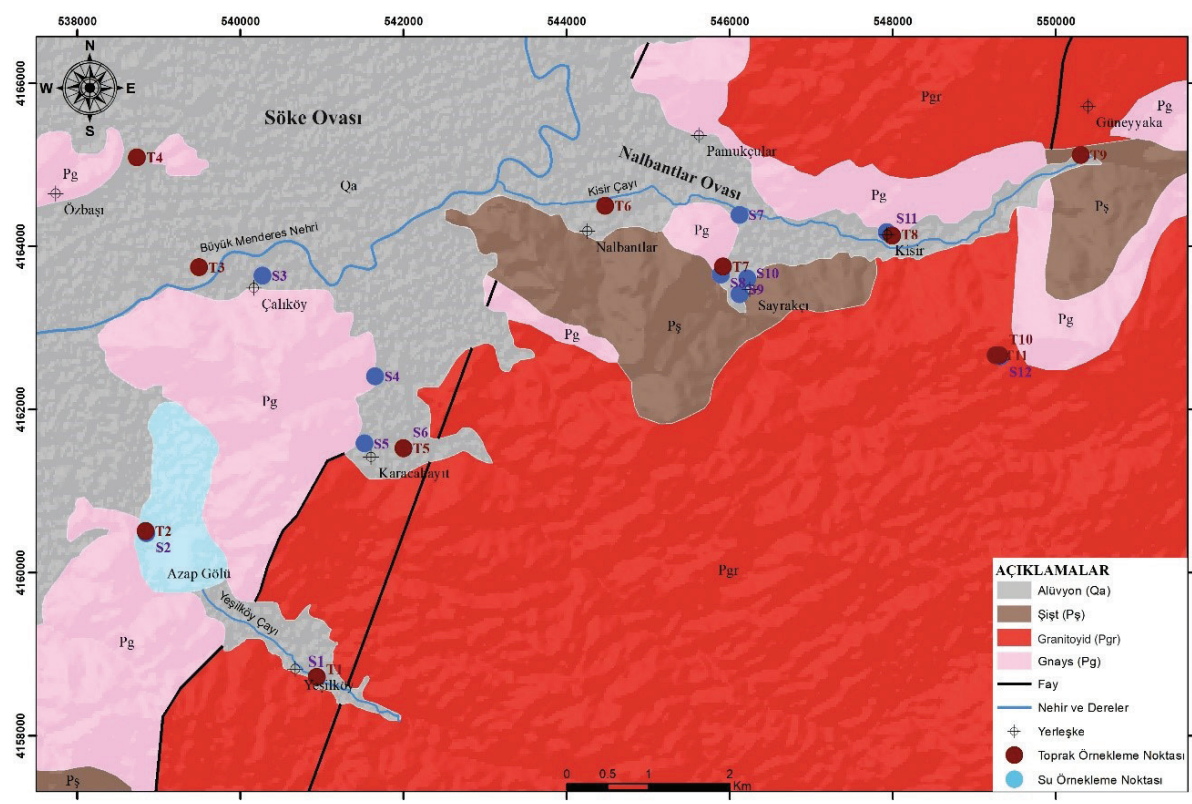

Şekil 2. Çalışma alanının örnek noktaları işaretlenmiş jeoloji haritası (MTA, 2002).

Figure 2. Geological map of the study area with the sample points marked (MTA, 2002).

T6 toprağı Kisir Çay1 yakınından Nalbantlar bölgesindeki tarım topraklarından örneklenmiştir. Şist birimi ve Kisir Çayı sedimanları ile etkileşim halindedir. S7 kuyusu 10 metre derinlikte olup içme ve sulama amaçlı tüketilmektedir. Gnays birimi ile alüvyon dokanağına yakındır ve Kisir Çayı ile etkileşim halindedir. T7 toprağ gnays birimi yakınında, tarım arazisinden örneklenmiştir. S8, S9 ve S10 yeraltı suyu örneklemeleri ve T7 toprağ Sayrakçı bölgesini temsil etmektedir. 40 metre derinliğindeki S8 kuyusundan üretilen yeraltı suyu sulama amaçlı tüketilmekteyken, 10'ar metre derinlikteki S9 ve S10 kuyularından üretilen yeraltı suları içme amaçlı tüketilmektedir. T8 toprak örneklemesi Kisir bölgesinin tarım arazilerini temsil etmektedir. S11 yeraltı suyu ise yaklaşık 10 metre derinlikte kuyudan örneklenmiştir. Bölgedeki yaklaşık aynı derinlikteki birçok kuyu suyu içme amaçlı tüketilmektedir. T9 toprağ1 ovanın en doğusunda şişt birimi yakınında yer almaktadır. Civarda yeraltı suyu üretim kuyusuna rastlanmamıştır. Kisir Çayı suları, içme ve sulama amaçlı tüketilmektedir. T10 ve T11 toprak örnekleri ise gnays ve granitoyid birimleri dokanağı yakınından örneklenmiştir. Bölgede yeraltı su kuyusu bulunmamakta, tarımsal etkinlik ve yerleşik nüfus düzlüklerle sınırlıdır. S12 kaynağı bölgenin içme ve sulama ihtiyacının karşılandığı düşük debili kaynak suyudur. T10 ve T11 örnekleri birbirine çok yakın noktalardan örnekleme yapılmıştır. T10 toprağı S12 kaynağının çıktığı bölgeyi temsil ederken, T11 toprağı yakınındaki tarım arazisinden örneklenmiştir. Toprak örneklerinin bölgeyi en iyi şekilde temsil edebilmesi için ağıllardan uzakta, herhangi atık ya da gübrenin depolanmadığ 1 alanlar tercih edilmiştir. Su örneklerinin fiziksel parametreleri, kimyasal analiz sonuçları ve kullanım amaçları Çizelge 1 'de listelenmiştir. Majör iyonlar $(\mathrm{Ca}, \mathrm{Mg}, \mathrm{K}$, $\mathrm{Na}, \mathrm{Cl}, \mathrm{SO}_{4}$ ve $\mathrm{HCO}_{3}$ ) $\mathrm{mg} / \mathrm{L}$ olarak, diğerleri $\mu \mathrm{g} / \mathrm{L}$ olarak verilmiştir. Toprak örneklerinin kimyasal analiz sonuçları Çizelge 2'de verilmiştir. 
Küçüksümbül, Tarcan

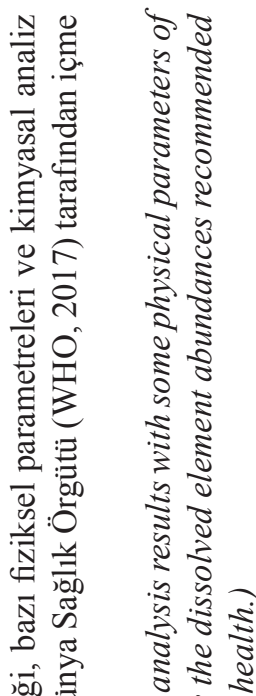

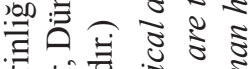

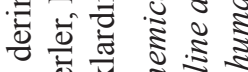

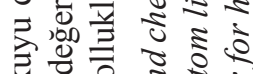
西

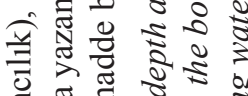
दี

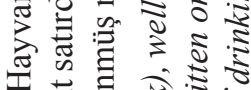

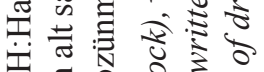

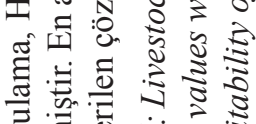
की: की 造永.

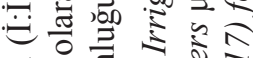
毛

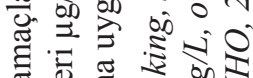
है चु

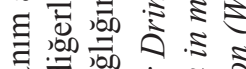

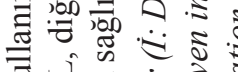

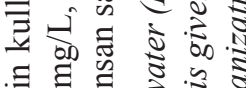
己 $*$ \&े

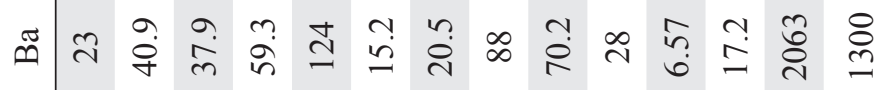

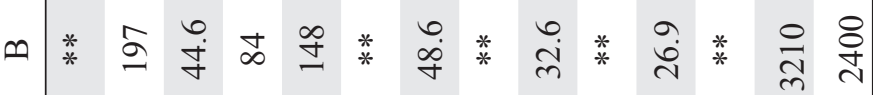

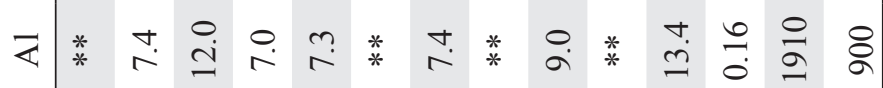

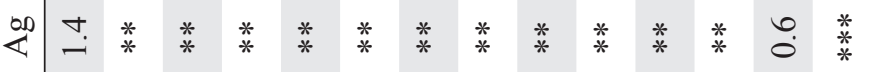

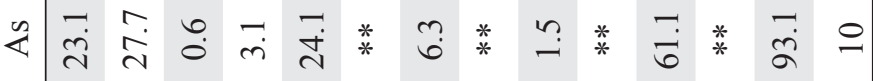

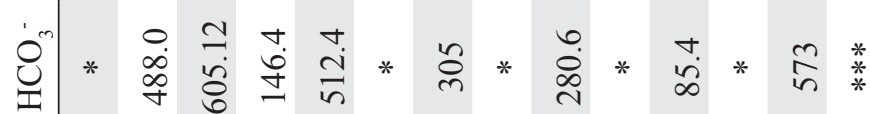

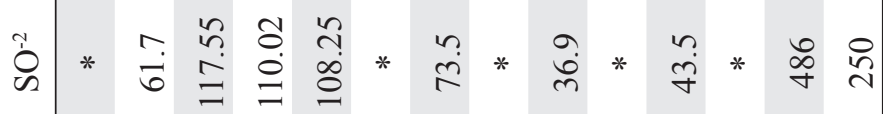

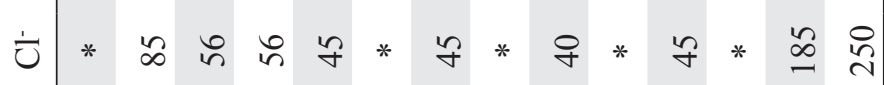

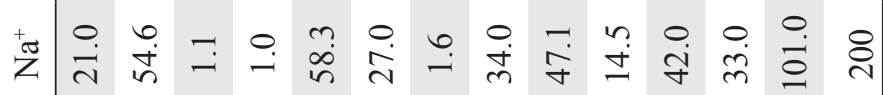

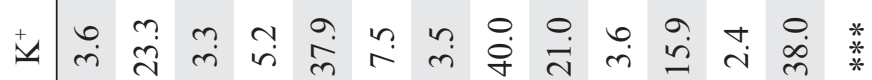

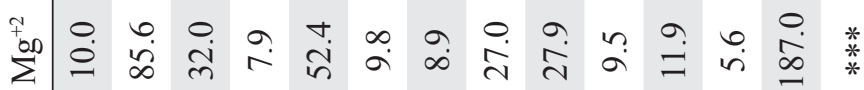
†

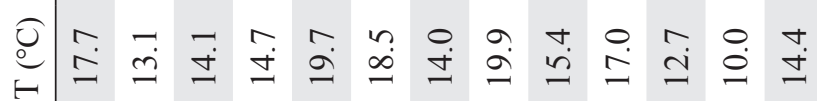

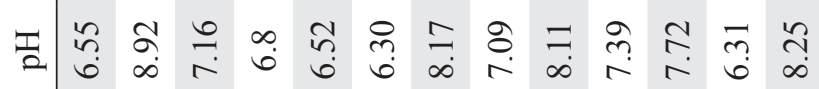
:

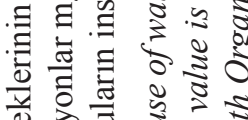

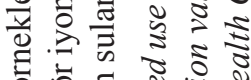
:0:

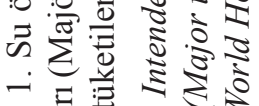

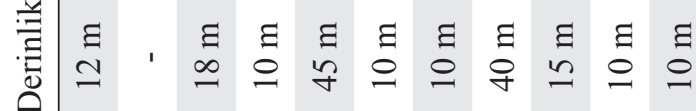

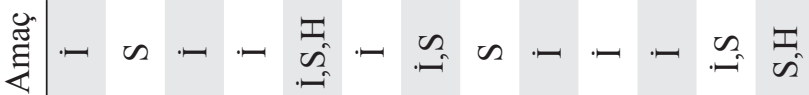

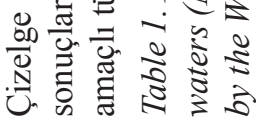

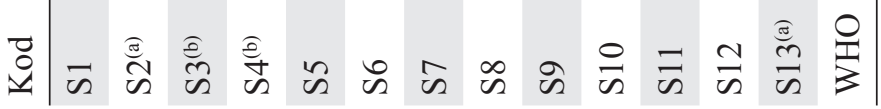




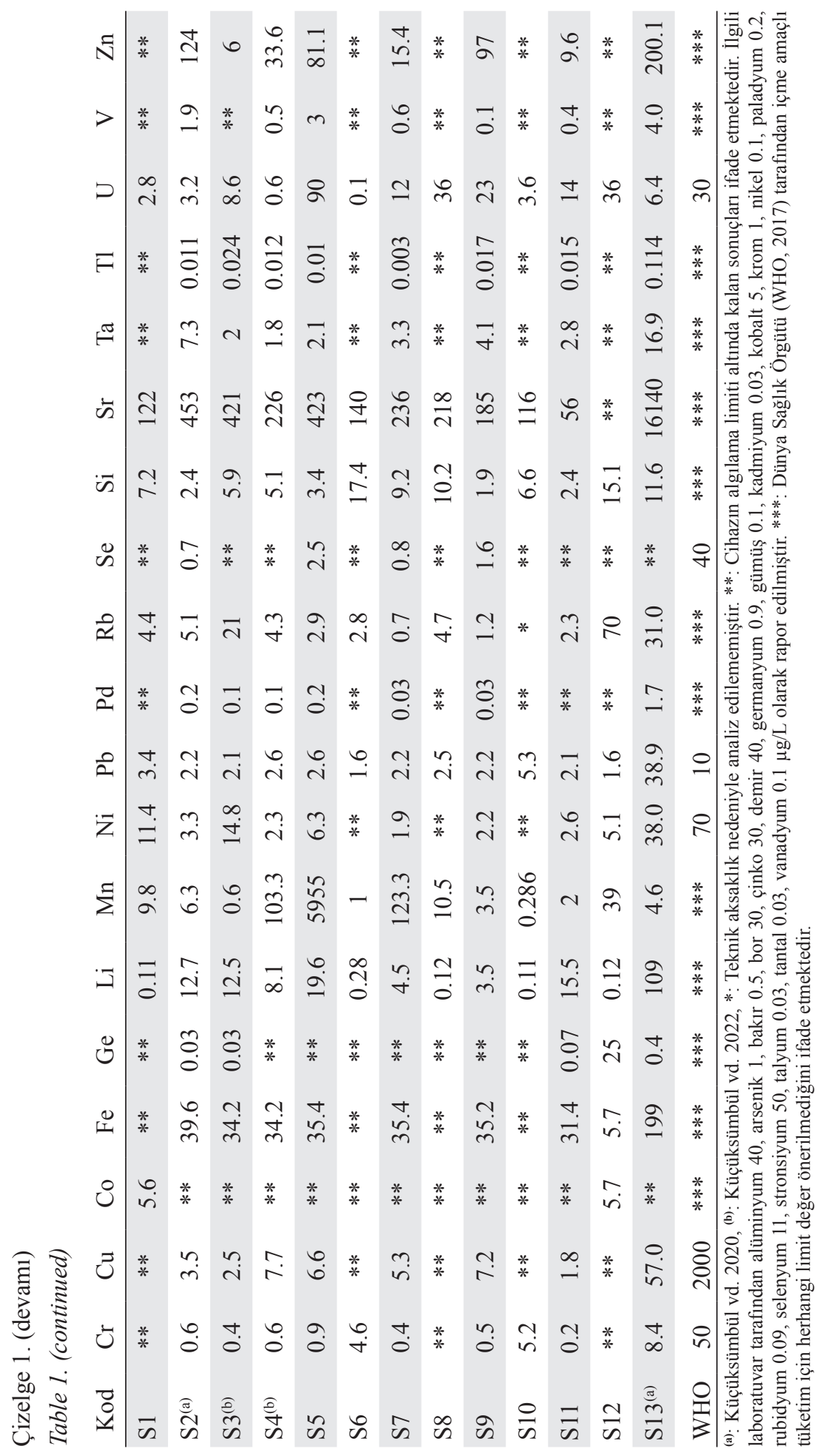


Küçüksümbül, Tarcan

Çizelge 2. Toprak örneklerinin kimyasal analiz sonuçları (Söke Ovası ve civarı için kullanılan temel değerler (TD) koyu yazılmıştır. Tüm değerler $\mathrm{mg} / \mathrm{kg}$ olarak verilmiştir.).

Table 2. Chemical analysis results of soil samples (Background values used for Söke Plain and its surroundings are written in bold. All values are given in $\mathrm{mg} / \mathrm{kg}$ ).

\begin{tabular}{cccccccccccc} 
Kod & $\mathrm{As}$ & $\mathrm{Cd}$ & $\mathrm{Co}$ & $\mathrm{Cr}$ & $\mathrm{Cu}$ & $\mathrm{Hg}$ & $\mathrm{Ni}$ & $\mathrm{Pb}$ & $\mathrm{Sb}$ & $\mathrm{U}$ & $\mathrm{Zn}$ \\
\hline $\mathrm{T} 1$ & 14.9 & $*$ & 420.9 & 13.7 & 3.7 & $*$ & 8.5 & 10.5 & 0.50 & 4.6 & 18.0 \\
$\mathrm{~T}^{\mathrm{a}}$ & 36.9 & 0.03 & 16.4 & 54.7 & 23.9 & 0.007 & 20.9 & 2.7 & 0.42 & 1.4 & 16.7 \\
$\mathrm{~T}^{\mathrm{a}}$ & 9.7 & 0.13 & 22.3 & 561.1 & 19.2 & 0.031 & 274.2 & 9.1 & 0.35 & 0.9 & 42.9 \\
$\mathrm{~T}^{\mathrm{a}}$ & 14.8 & 0.18 & 28.7 & 355.8 & 29.6 & 0.065 & 305.4 & 14.3 & 0.36 & 1.9 & 57.2 \\
$\mathrm{~T} 5$ & 4.3 & $*$ & 191.6 & 20.5 & 5.2 & $*$ & 9.3 & 6.6 & 0.50 & 3.4 & 25.0 \\
$\mathrm{~T} 6$ & 29.2 & 0.19 & 19.8 & 61.6 & 21.7 & 0.038 & 24.7 & 9.7 & 6.77 & 2.3 & 57.7 \\
$\mathrm{~T} 7$ & 32.4 & 0.2 & 89.3 & 61.6 & 23.4 & $*$ & 25.4 & 12.4 & 1.60 & 3.5 & 89.0 \\
$\mathrm{~T} 8$ & 11.0 & 0.15 & 14.0 & 68.4 & 20.7 & 0.056 & 23.5 & 10.6 & 0.59 & 5.2 & 55.8 \\
$\mathrm{~T} 9$ & 6.1 & $*$ & 95.0 & 34.2 & 10.9 & $*$ & 14.7 & 5.1 & 0.40 & 2.9 & 31.0 \\
$\mathrm{~T} 10$ & 9.6 & $*$ & 69.3 & 27.4 & 9.1 & $*$ & 9.5 & 12.2 & 0.20 & 14.7 & 26.0 \\
$\mathrm{~T} 11$ & 2.1 & $*$ & 94.7 & 13.7 & 4.5 & $*$ & 5.7 & 6.1 & 0.10 & 5.7 & 15.0 \\
TD $^{\mathbf{a}}$ & $\mathbf{7 . 5}$ & $\mathbf{0 . 1 2}$ & $\mathbf{2 6}$ & $\mathbf{2 0 0}$ & $\mathbf{2 2}$ & $\mathbf{0 . 0 9}$ & $\mathbf{1 5 0}$ & $\mathbf{1 5}$ & $\mathbf{0 . 3 5}$ & $\mathbf{2 . 1}$ & $\mathbf{4 0}$ \\
\hline
\end{tabular}

a: Küçüksümbül vd. 2022'den alınmıştır.

*: Cihazın algılama limiti altında kalan sonuçları ifade etmektedir. Kadmiyum için $0.1 \mathrm{mg} / \mathrm{kg}$, cıva için $0.01 \mathrm{mg} / \mathrm{kg}$ olarak rapor edilmiştir.

\section{Toprak Kirliliği Değerlendirme Kriterleri}

Metal ve yarı metallerce zengin kayaçların ayrışması, ana jeojenik girdilerin nedeni olarak açıklanabilir. Noktasal olarak herhangi zenginleşme olup olmadığının anlaşılabilmesi için, bölgedeki kayaçların kimyası göz önünde bulundurularak insan etkinliğinin kısıtlı olduğu topraklardan alınan örneklerden temel değer oluşturulabilmektedir. Bu çalışmada, Söke Ovası drenaj ağındaki kayaçlar (mermer, karbonat, gnays) ve topraklar üzerinden hesaplanan temel değer kullanılmıştır (Küçüksümbül vd., 2022). Topraktaki kirletici maddelerin üst limit değerleri devletler tarafından yasallaştırılmaktadır. Gıda ve Tarım Örgütü (FAO) gibi bazı uluslararası kuruluşlar tarafından yapılan çalışmalarla da sinır değerler önerilmektedir. Türkiye (TS, 2010), Finlandiya (MEF, 2007), Kanada (CSQG, 2010) ile Gıda ve Tarım Örgütü (FAO, 2007) tarafından kullanılan limit değerler ve literatür taraması sonucu elde edilen üst kitasal kabuk ortalama değerleri (Goldschmidt, 1937; Turekian ve Wedepohl, 1961; Wedepohl, 1995; McLennan, 2001; Rudnick vd., 2003), Söke Ovası temel değerleri ile birlikte Çizelge 3 'de listelenmiştir.

\section{Zenginleşme Faktörü}

Zenginleşme faktörü (ZF), kontaminasyon çalışmalarında yaygın olarak kullanılmaktadır (Çevik vd., 2009; Bourennane vd., 2010; Zhao vd., 2015; Sakan vd., 2016; Akinci vd., 2019). $\mathrm{ZF}$, topraktaki metal birikimini matematiksel olarak ifade etmek için kullanılır. Bu yöntem; arsenik (As), kadmiyum (Cd), kobalt (Co), krom $(\mathrm{Cr})$, bakır $(\mathrm{Cu})$, cıva $(\mathrm{Hg})$, nikel $(\mathrm{Ni})$, kurşun $(\mathrm{Pb})$, antimon $(\mathrm{Sb})$, uranyum $(\mathrm{U})$ ve çinko $(\mathrm{Zn})$ olmak üzere 11 element içinde kullanılmıştır. Zenginleşme faktörü değeri, aşağıdaki yer alan eşitlik kullanılarak hesaplanmaktadır (Sutherland, 2000): 
Çizelge 3. Eser elementlerin literatürdeki üst kıtasal kabuk değerleri (a), Söke Ovası temel değeri ve toprak numunelerinin en düşük, en fazla ve ortalama değerleri (b), Türkiye (TS), Finlandiya (MEF), Kanada (CSQG) ve Birleşmiş Milletler (FAO) tarımsal toprak eşik değerleri (c) (Tüm değerler mg/kg olarak verilmiştir).

Table 3. Trace element composition of the upper continental crust in literatüre (a), background value (TD) suggested in this study and minimum, maximum, average values of metal(loid)s accumulation of soil samples (b), threshold values of agricultural soil quality regulations of Turkey (TS), Finland (MEF), Canada (CSQG), and the United Nations (FAO) (c) (All values are given in $\mathrm{mg} / \mathrm{kg}$ ).

\begin{tabular}{|c|c|c|c|c|c|c|c|c|c|c|c|c|c|}
\hline & & As & $\mathrm{Cd}$ & $\mathrm{Co}$ & $\mathrm{Cr}$ & $\mathrm{Cu}$ & $\mathrm{Hg}$ & $\mathrm{Ni}$ & $\mathrm{Pb}$ & $\mathrm{Sb}$ & $\mathrm{U}$ & $\mathrm{V}$ & $\mathrm{Zn}$ \\
\hline \multirow{5}{*}{ (a) } & $\begin{array}{l}\text { Goldschmidt } \\
\text { (1937) }\end{array}$ & 5 & 0.5 & 40 & 200 & 100 & 0.5 & 100 & 16 & 1 & 4.0 & 100 & 40 \\
\hline & $\begin{array}{l}\text { Turekian ve } \\
\text { Wedepohl } \\
\text { (1961) }\end{array}$ & 13 & 0.3 & 19 & 90 & 45 & 0.4 & 68 & 20 & 1.5 & 3.7 & 130 & 95 \\
\hline & $\begin{array}{l}\text { Wedepohl } \\
(1995)\end{array}$ & 2 & 0.102 & 11.6 & 35 & 14.3 & 0.056 & 18.6 & 17 & 0.31 & 2.5 & 53 & 52 \\
\hline & $\begin{array}{l}\text { McLennan } \\
\text { (2001) }\end{array}$ & 1.5 & 0.098 & 17 & 83 & 25 & - & 44 & - & 0.2 & 2.8 & 107 & 71 \\
\hline & $\begin{array}{l}\text { Rudnick vd. } \\
\text { (2003) }\end{array}$ & 4.8 & 0.09 & 17.3 & 92 & 28 & 0.05 & 47 & 17 & 0.4 & 2.7 & 97 & 67 \\
\hline \multirow{4}{*}{ (b) } & Temel Değer* & 7.5 & 0.12 & 26 & 200 & 22 & 0.09 & 150 & 15 & 0.35 & 2.1 & 45 & 40 \\
\hline & En düşük & 2.1 & 0.03 & 14 & 13.7 & 3.7 & $<0.01$ & 5.7 & 2.7 & 0.10 & 0.9 & 12 & 15 \\
\hline & En fazla & 36.9 & 0.20 & 420.9 & 561.1 & 29.6 & 0.065 & 305.4 & 14.3 & 6.77 & 14.7 & 61 & 89 \\
\hline & Ortalama & 15.5 & - & 96.5 & 115.7 & 15.6 & - & 65.6 & 9.0 & 1.07 & 4.2 & 27.5 & 39.5 \\
\hline \multirow{4}{*}{ (c) } & TS (2010) & 3 & 27 & 5 & 10 & 514 & 3 & 13 & 135 & 2 & - & 256 & 6811 \\
\hline & MEF (2007) & 5 & 1 & 20 & 100 & 100 & 0.5 & 50 & 60 & 2 & - & 100 & 200 \\
\hline & CSQG (2010) & 12 & 1.4 & 40 & 64 & 63 & 6.6 & 45 & 70 & 20 & 23 & 130 & 250 \\
\hline & FAO (2007) & 1 & 1 & - & 100 & 200 & 2 & 100 & 200 & - & - & - & 150 \\
\hline
\end{tabular}

*: Küçüksümbül vd. (2022)'den alınmıştır.

$\mathrm{ZF}=\frac{\left(\frac{\mathrm{C}_{n}}{\mathrm{C}_{\text {ref }}}\right) \text { Toprak }}{\left(\frac{B_{n}}{B_{\text {ref }}}\right) \text { Temel Değer }}$

$\mathrm{C}_{\mathrm{n}}$ seçilen elementin her topraktaki bolluğu (Çizelge 2), $\mathrm{C}_{\text {ref }}$ her topraktaki referans elementin bolluğu, $\mathrm{B}_{\mathrm{n}}$ hesaplanan temel değeri (Çizelge 3), referans elementin bolluğudur. Çalışma kapsamında referans element olarak alüminyum (Al) seçilmiştir. Sutherland (2000)'e göre ZF değeri 2'den küçük olduğunda, toprakta minimum zenginleşme veya hiç zenginleşme yok olarak sinıflandirılır. Zhang ve Liu (2002) tarafından yapılan çalışmada 0.5 ile 1.5 arasındaki eser element bolluğu, zenginleşmenin tamamen doğal süreçlerden kaynaklandığını göstermektedir. $\mathrm{Bu}$ nedenle, zenginleşme katsayısı 1.5 ila 2 olan topraklar, düşük kirlenme olarak gruplandırılmıştır. 2 ile 5 arası değerler 
Küçüksümbül, Tarcan

kısmen kirlenme, 5 ile 20 arası önemli ölçüde kirlenme, 20 ile 40 arası fazlasiyla kirlenme ve 40'dan büyük değerler ise aşırı derece kirlenme olarak sinıflandırılır (Sutherland, 2000).

\section{Toprakların İnsan Sağlı̆̆ı Risk Değerlendirmesi}

Topraktan kaynaklanabilecek kanserojen risk (KR) ve kanserojen olmayan risk katsay1s1 (RK) soluma, yutma (oral yolla) ve deriyle temas olarak 3 kategoride incelenmektedir (Lim vd., 2008, Wongsosuluk vd., 2014, PeñaFernández vd., 2014). Kanserojen olmayan toplam risk (TRK) 3 kategorinin toplanmas1 ile elde edilir. 1'den büyük olması riskli kabul edilir (US EPA, 1992). Her kategori için farklı hesaplamalar yapılmaktadır. Günlük kronik alım (GKA) değerinin, oral referans doza (RfD) bölünmesi ile oral yolla ve deri ile temasla gerçekleşebilecek kanserojen olmayan risk hesaplanabilmektedir. GKA değerinin referans konsantrasyona (RfC) bölünmesi ile soluma yoluyla gerçekleşebilecek kanserojen olmayan risk hesaplanabilmektedir. GKA değerinin eğim faktörü (SP) ile çarpılmasıyla ise kanser riski (KR) belirlenebilmektedir (RAIS, 2021a). İlgili eşitlikler aşağıda sıralanmıştır. Eşitliklerdeki kısaltmaların tanımları, birimleri ve değerleri (US EPA, 2004). ile referans doz (RfD), referans konsantrasyon (RfC) ve eğim faktörü (SP) değerleri (US EPA IRIS, 2021). Çizelge 4 ve 5 'te listelenmiştir. Civanın $(\mathrm{Hg})$ oral referans doz değeri $\left(\mathrm{RfD}_{\text {oral }}\right)$ ile kurşunun $(\mathrm{Pb})$ eğim faktör değeri ( $\mathrm{SF}_{\text {oral }}$ ) RAIS (2021b)'den alınmıştır. Kadmiyum (Cd), kobalt (Co), krom (Cr), nikel (Ni) için eğim faktör değerleri $\left(\mathrm{SF}_{\text {soluma }}\right)$ FerreiraBaptista ve De Miguel (2005)'den ve kurşunun $(\mathrm{Pb})$ oral referans doz değeri $\left(\mathrm{RfD}_{\text {ora }}\right)$ PeñaFernández vd. (2014)'den alınmıştır. Deriyle temasın referans doz değerinin hesabı için $\mathrm{RfD}_{\text {oral }}$ değeri $\mathrm{ABS}_{\mathrm{GI}}$ ile çarpılmış olup deriyle temasta kullanılacak eğim faktörü ise $\mathrm{SF}_{\text {oral }}$ değerinin
$\mathrm{ABS}_{\mathrm{GI}}$ değerine bölümü ile bulunabilmektedir (RAIS, 2021a). Çocuklar için; maruz kalma süresi (ED) 6 y1l, vücut ağırlığ1 (BW) $6 \mathrm{~kg}$, yutma oran1 $\left(\right.$ Oral $\left._{R}\right) 100 \mathrm{mg} /$ gün, soluma oranı $\left(\right.$ Soluma $\left._{\mathrm{R}}\right) 7.6 \mathrm{~m}^{3} /$ gün ve maruz kalan cilt yüzey alanı (SA) $2200 \mathrm{~cm}^{2}$ olarak hesaplanmıştır. Deri emilim faktörü $\left(\mathrm{ABS}_{\mathrm{d}}\right.$ ) arsenik için 0.03 , diğerleri için ise 0.001 olarak alınmıştır (Ferreira-Baptista ve De Miguel, 2005; Luo vd., 2012).

$$
\begin{aligned}
& G K A_{\text {soluma }}=\frac{C \times E F \times \text { Soluma }_{R} \times E D}{P E F \times 24 \times A T_{n c}} \\
& G K A_{\text {oral }}=\frac{C \times \text { Oral }_{R} \times E F \times E D \times C F}{B W \times L T} \\
& G K A_{\text {deri }}=\frac{C \times S A \times A F \times A B S_{d} \times E F \times E D}{B W \times A T_{n c}} \times 10^{-6} \\
& R K=\frac{G K A}{R_{f d}} \\
& T R K=\sum R K_{\text {soluma }}+R K_{\text {oral }}+R K_{\text {deri }} \\
& K R=G K A \times S F
\end{aligned}
$$

\section{Su Kirliliği Değerlendirme Kriterleri}

İçme sularındaki kirletici maddelerin üst limit değerleri devletler tarafindan yasallaştırılmaktadır. Dünya Sağlık Örgütü (WHO) gibi bazı uluslararası kuruluşlar tarafından yapılan çalışmalarla da kılavuz değerler önerilmektedir. Evrensel olarak kabul gören genel bir standart olmamakla birlikte birçok limit değer konusunda yasalar ve uluslararası kuruluşlar hem fikir olmuş denilebilir. $\mathrm{Bu}$ çalışma kapsamında Avrupa Birliği (EU, 2014), Türkiye (TS, 2013), Amerika Birleşik Devletleri (US EPA, 2018) ve Dünya Sağlık Örgütü (WHO, 2017) tarafından önerilen limit değerleri karşılaştırılmıştır. Suların oral referans doz değeri (Pena-Fernandez vd., 2014; US EPA IRIS, 2021) ve eğim faktörleri (FerreiraBaptista ve De Miguel, 2005; RAIS 2021b; US EPA IRIS, 2021) Çizelge 6'da verilmiştir. 
Çizelge 4. Eşitliklerde kullanılan kısaltmaların tanımı, birimi ve değerleri.

Table 4. Definitions, units and values of abbreviations used in mention equations.

\begin{tabular}{|c|c|c|c|}
\hline Kisaltma & Tanım & Birim & Değer \\
\hline $\mathrm{ABS}_{\mathrm{d}}$ & Deri emilim faktörü & - & $\begin{array}{l}\text { As için 0.03, } \\
\text { diğerleri } 0.001\end{array}$ \\
\hline $\mathrm{AF}$ & Cilde tutunma faktörü & $\mathrm{mg} / \mathrm{cm}^{2}$ & 0.2 \\
\hline $\mathrm{AT}_{\mathrm{c}}$ & Ortalama Zaman & gün & LT \\
\hline $\mathrm{AT}_{\mathrm{nc}}$ & Ortalama Zaman & gün & ED \\
\hline BW & Vücut Ağırlı̆̆ 1 & $\mathrm{~kg}$ & 70 \\
\hline $\mathrm{C}$ & Madde Bolluğu & $\mathrm{mg} / \mathrm{kg}$ & Çizelge 2 \\
\hline $\mathrm{CF}$ & Dönüşüm Faktörü & - & $1.00 \mathrm{E}-05$ \\
\hline ED & Maruz kalma Süresi & y1l & 40 \\
\hline $\mathrm{EF}$ & Maruz kalma Sıklı̆̆ & gün/y1l & 313 \\
\hline ET & Maruz kalma Zamanı & sa/gün & 24 \\
\hline $\operatorname{Oral}_{R}$ & Yutma Oranı & mg/gün & 200 \\
\hline Soluma $_{\mathrm{R}}$ & Soluma Oranı & $\mathrm{m}^{3} /$ gün & 20 \\
\hline LT & Yaşam Süresi & gün & 28579 \\
\hline PEF & Partikül Emisyon Faktörü & $\mathrm{m}^{3} / \mathrm{kg}$ & $1.36 \mathrm{E}+09$ \\
\hline SA & $\begin{array}{c}\text { Maruz kalan cilt yüzey } \\
\text { alanı }\end{array}$ & $\mathrm{cm}^{2}$ & 5700 \\
\hline SF & Eğim Faktörü & $\mathrm{mg}^{-1} \cdot \mathrm{gün}^{-1} \cdot \mathrm{kg}$ & Çizelge 5 \\
\hline
\end{tabular}

Çizelge 5. Eşitliklerde kullanılan referans doz (RfD), referans konsantrasyon (RfC), eğim faktörü (SF) ve absorpsiyon oranı $\left(\mathrm{ABS}_{\mathrm{GI}}\right)$ değerleri.

Table 5. Reference dose (RfD), reference concentration $(R f C)$, slope factor $(S F)$ and absorption rate $\left(A B S_{G I}\right)$ values used in the equations.

\begin{tabular}{cccccccc} 
& $\mathrm{RfD}_{\text {oral }}$ & $\mathrm{RfC}_{\text {soluma }}$ & $\mathrm{RfD}_{\text {deri }}$ & $\mathrm{ABS}_{\mathrm{GI}}$ & $\mathrm{SF}_{\text {oral }}$ & $\mathrm{SF}_{\text {soluma }}$ & $\mathrm{SF}_{\text {deri }}$ \\
\hline $\mathrm{As}$ & $3.00 \mathrm{E}-04$ & $1.50 \mathrm{E}-05$ & $3.00 \mathrm{E}-04$ & 1 & $1.50 \mathrm{E}+00$ & $1.51 \mathrm{E}+00$ & $1.50 \mathrm{E}+00$ \\
$\mathrm{Cd}$ & $5.00 \mathrm{E}-04$ & $1.00 \mathrm{E}-05$ & $1.25 \mathrm{E}-05$ & 0.025 & - & $6.30 \mathrm{E}+00$ & \\
$\mathrm{Co}$ & $3.00 \mathrm{E}-04$ & $6.00 \mathrm{E}-06$ & $3.00 \mathrm{E}-04$ & 1 & - & $9.80 \mathrm{E}+00$ & \\
$\mathrm{Cr}$ & $3.00 \mathrm{E}-03$ & $1.00 \mathrm{E}-04$ & $7.50 \mathrm{E}-05$ & 0.025 & $5.00 \mathrm{E}-01$ & $4.20 \mathrm{E}+00$ & $2.00 \mathrm{E}+01$ \\
$\mathrm{Cu}$ & $4.00 \mathrm{E}-02$ & - & $4.00 \mathrm{E}-02$ & 1 & - & - & - \\
$\mathrm{Hg}$ & $1.60 \mathrm{E}-04$ & $3.00 \mathrm{E}-04$ & $1.60 \mathrm{E}-04$ & 1 & - & - & - \\
$\mathrm{Ni}$ & $2.00 \mathrm{E}-02$ & $9.00 \mathrm{E}-05$ & $8.00 \mathrm{E}-04$ & 0.04 & - & $8.40 \mathrm{E}+00$ & - \\
$\mathrm{Pb}$ & $3.50 \mathrm{E}-03$ & - & $3.50 \mathrm{E}-03$ & 1 & $8.50 \mathrm{E}-03$ & - & $8.50 \mathrm{E}-03$ \\
$\mathrm{Sb}$ & $4.00 \mathrm{E}-04$ & $3.00 \mathrm{E}-04$ & $6.00 \mathrm{E}-05$ & 0.15 & - & - & - \\
$\mathrm{U}$ & $2.00 \mathrm{E}-04$ & $4.00 \mathrm{E}-05$ & $2.00 \mathrm{E}-04$ & 1 & - & - & - \\
$\mathrm{Zn}$ & $3.00 \mathrm{E}-01$ & - & $3.00 \mathrm{E}-01$ & 1 & - & - & - \\
\hline
\end{tabular}


Küçüksümbül, Tarcan

Çizelge 6. Elementlerin oral referans doz $\left(\mathrm{mg}\right.$.gün. $\left.\mathrm{kg}^{-1}\right)$ ve eğim faktörü değerleri $\left(\mathrm{mg}^{-1} \cdot \mathrm{gün}^{-1} \cdot \mathrm{kg}\right)$ ile içme suyu limit değerleri $(\mathrm{mg} / \mathrm{L})$.

Table 6. Oral reference dose (mg.day. $\left.\mathrm{kg}^{-1}\right)$ and slope factor $\left(\mathrm{mg}^{-1}\right.$. day $\left.{ }^{-1} \cdot \mathrm{kg}\right)$ values of elements with limit values of water for drinking purposes $(\mathrm{mg} / \mathrm{L})$.

\begin{tabular}{lcccccccccc}
\hline & $\mathrm{As}$ & $\mathrm{B}$ & $\mathrm{Ba}$ & $\mathrm{Cd}$ & $\mathrm{Cr}$ & $\mathrm{Cu}$ & $\mathrm{Ni}$ & $\mathrm{Pb}$ & $\mathrm{U}$ & $\mathrm{Zn}$ \\
$\begin{array}{l}\text { Oral Referans Doz } \\
\text { (RfD) }\end{array}$ & 0.0003 & 0.2 & 0.2 & 0.0005 & 0.003 & $0.04^{(\mathrm{a})}$ & 0.02 & $0.0035^{(\mathrm{b})}$ & 0.0002 & 0.3 \\
Son revize (RfD) & 1991 & 2004 & 2005 & 1989 & 1998 & - & 1991 & - & 1989 & 2005 \\
& & & & & & & & & & \\
Eğim Faktörü (SF) & 1.5 & - & - & - & $0.5^{(\mathrm{c})}$ & - & - & $0.0085^{(\mathrm{a})}$ & - & - \\
WHO (2017) & 0.01 & 2.4 & 1.3 & 0.003 & 0.05 & 2 & 0.07 & 0.01 & 0.03 & - \\
EU (2014) & 0.01 & 1 & - & 0.005 & 0.05 & 2 & 0.02 & 0.01 & - & - \\
US EPA (2018) & 0.01 & - & 2 & 0.005 & 0.1 & 1.3 & - & 0.015 & 0.03 & - \\
TS (2013) & 0.01 & 1 & - & 0.005 & 0.05 & 2 & 0.02 & 0.01 & - & - \\
\hline
\end{tabular}

${ }^{(a)}$ : RAIS 2021b, ${ }^{(b)}$ : Peña-Fernández vd., 2014, ${ }^{(c)}$ : Ferreira-Baptista ve De Miguel, 2005'den alınmıştır.

Çizelge 7. Günlük kronik alımın (GKA) hesabında kullanılan parametrelerin tanımı, birimi ve değerleri.

Table 7. Definition, unit and values of parameters used in the calculation of chronic daily intake (GKA).

\begin{tabular}{cccc}
\hline Parametreler & Tanım & Birim & Değer \\
C & Toplam çözünmüş madde miktarı & $\mu \mathrm{g} / \mathrm{L}$ & Çizelge 1 \\
IR & Günlük su alım miktarı & $\mathrm{L} / \mathrm{Gün}$ & 3.1 \\
EF & Maruz kalma sıklığı & Gün/Yıl & 365 \\
ED & Maruz kalma süresi & Yıl & 45 \\
BW & Vücut ağırlığ 1 & $\mathrm{Kg}$ & 70 \\
LT & Ortalama ömür & Gün & 28579 \\
& $\mu \mathrm{g} / \mathrm{L}$ değerini mg/L'ye çevirme & & 0.001 \\
\hline $0^{-3}$ & amaçlı & - & \\
\hline
\end{tabular}

\section{İçme Sularının İnsan Sağlığı Risk Değerlendirmesi}

Uygulanan yöntem, içme suyunda analiz edilen elementlerin insan sağlığına olan etkisinin matematiksel olarak ifade edilebilmesi için kullanılmaktadır (Wongsasuluk vd., 2014; Saha vd., 2017; Shil ve Shingh, 2019; Prasad vd., 2020). Denklemin parametreleri ve değerleri Çizelge 7'de ifade edilmiştir. Günlük kronik alım (GKA) aşağıda yer alan eşitlik ile hesaplanmaktadır (US EPA, 1992):

$\mathrm{GKA}=\frac{\mathrm{C} \times 10^{-3} \times \mathrm{IR} \times \mathrm{EF} \times \mathrm{ED}}{\mathrm{BW} \times \mathrm{LT}}$

Oral referans doz (RfD) değeri, araştırmalar sonucunda belirlenen dozu ifade eder (US EPA IRIS, 2021). Kanserojen olmayan sağlık riski (TRK), her bir çözünmüş madde için tehlike 
katsayısı (HQ) cinsinden ifade edilir. Kural olarak, HQ $\leq 1$ çok az endişe kaynağıdır, ancak HQ $\geq 1$ endişe riski taşır (US EPA 1999). Her elementin risk katsayısı (HQ), aşağıdaki verilen eşitlik kullanılarak hesaplanır.

$H Q=\frac{G K A}{R_{f} D}$

Kanserojen risk, bireyin arsenik (As) gibi tehlikeli elementlere ömür boyu maruz kalmasından kaynaklanan herhangi bir kanser türü geliştirme olasılığıdır ve aşağıdaki eşitlik kullanılarak hesaplanır.

$R_{c a}=G K A \times S F$

10-6'dan küçük değerler kanserojen risk açısından kabul edilebilir olarak sınıflandırılır. Tolere edilebilir risk $10^{-6}$ ile $10^{-4}$ arasinda değişmektedir, bu da 1 milyon kişide bir vaka ile 10 bin kişide bir vaka anlamına gelmektedir (Lim vd., 2008). 10 10'ün üzerindeki değerler kanserojen etkisi nedeniyle zararlı kabul edilir.

\section{BULGULAR}

\section{Toprak Kirliliği}

Çalışma alanının örnekleme noktaları işaretlenmiş uydu görüntüsü ve jeoloji haritası Şekil 1 ve Şekil 2'de gösterilmiştir. T3 ve T4 örnekleme noktaları BMN suları ile etkileşim halindeyken, T2 örneği Azap Gölü'nü temsil etmektedir. Diğer tüm topraklar yakınında yer alan kuyudan çekim yapılan yeraltı suyu ile sulanmaktadır. Örneklerin temel değerler ile kıyaslanmış kimyasal analiz sonuçları Şekil 3'de, zenginleşme faktörü sonuçları Çizelge 8 'de listelenmiştir. Toprakların çoğunda
As kirlenmesi tespit edilmiştir. T1 ve T3 topraklarında düşük kirlenme, T4, T6 ve T7 topraklarında kısmen kirlenme, T2 toprağında ise önemli ölçüde kirlenme belirlenmiştir. Gnays birimiyle etkileşimde olan topraklar, jeojenik girdi nedenli arsenik kirlenmesi gelişen bölgeler olarak yorumlanmıştır.

Co kirliliği, T1 ve T5 topraklarında önemli ölçüde gelişmiş olup T7, T9, T10 ve T11 topraklarında k1smen kirlenme düzeyindedir. T1 toprağının sulandığ1 S1 örneği ve T10 ile T11 topraklarının sulandığ $\mathrm{S} 12$ kaynağı, eşik değerin üzerinde Co tespit edilen yeraltı sularıdır. Diğer sularda Co değerleri $1 \mu \mathrm{g} / \mathrm{L}$ 'den düşük olarak analiz edilmişken, bu sularda sırasıyla 5.6 ve 5.7 $\mu \mathrm{g} / \mathrm{L}$ Co analiz edilmiştir. Bölgedeki mermer ve karbonatlardan alınan örneklerde $3.2 \mathrm{mg} / \mathrm{L}$ ile $9.9 \mathrm{mg} / \mathrm{L}$ arasında Co bulunmakta iken gnays biriminde $136.2 \mathrm{mg} / \mathrm{L}$ seviyesinde Co analiz edilmiştir (Küçüksümbül vd., 2022). Bölgede yoğun olarak görülen Co zenginleşmesi, jeojenik girdiye bağlı olarak yorumlanmıştır.

$\mathrm{Cr}$ ve $\mathrm{Ni}$ zenginleşmesi yalnızca $\mathrm{BMN}$ ile sulanan topraklarda belirlenmiştir. $\mathrm{Bu}$ durum $\mathrm{Cr}$ ve Ni kirlenmesinin, BMN etkisiyle geliştiğini göstermektedir. Sb zenginleşmesi T6 toprağında fazlasıyla kirlenme, T7 toprağında önemli ölçüde kirlenme düzeyindedir. As ile birlikte Sb zenginleşmesi iki yarı metalin bir arada birikimi ile açıklanabilecekken, bölgede As kirliliği görülen topraklarda Sb zenginliği T6 ve T7 toprakları hariç doğal süreç düzeyindedir. T6 ve T7 topraklarında antropojenik girdiden söz edilebilir. $Z n$ ve $C d$ kirliliği aynı topraklarda ve yakın seviyelerde olup tarımsal etkinlikten kaynaklanan antropojenik girdi olarak değerlendirilmiştir. 
Küçüksümbül, Tarcan
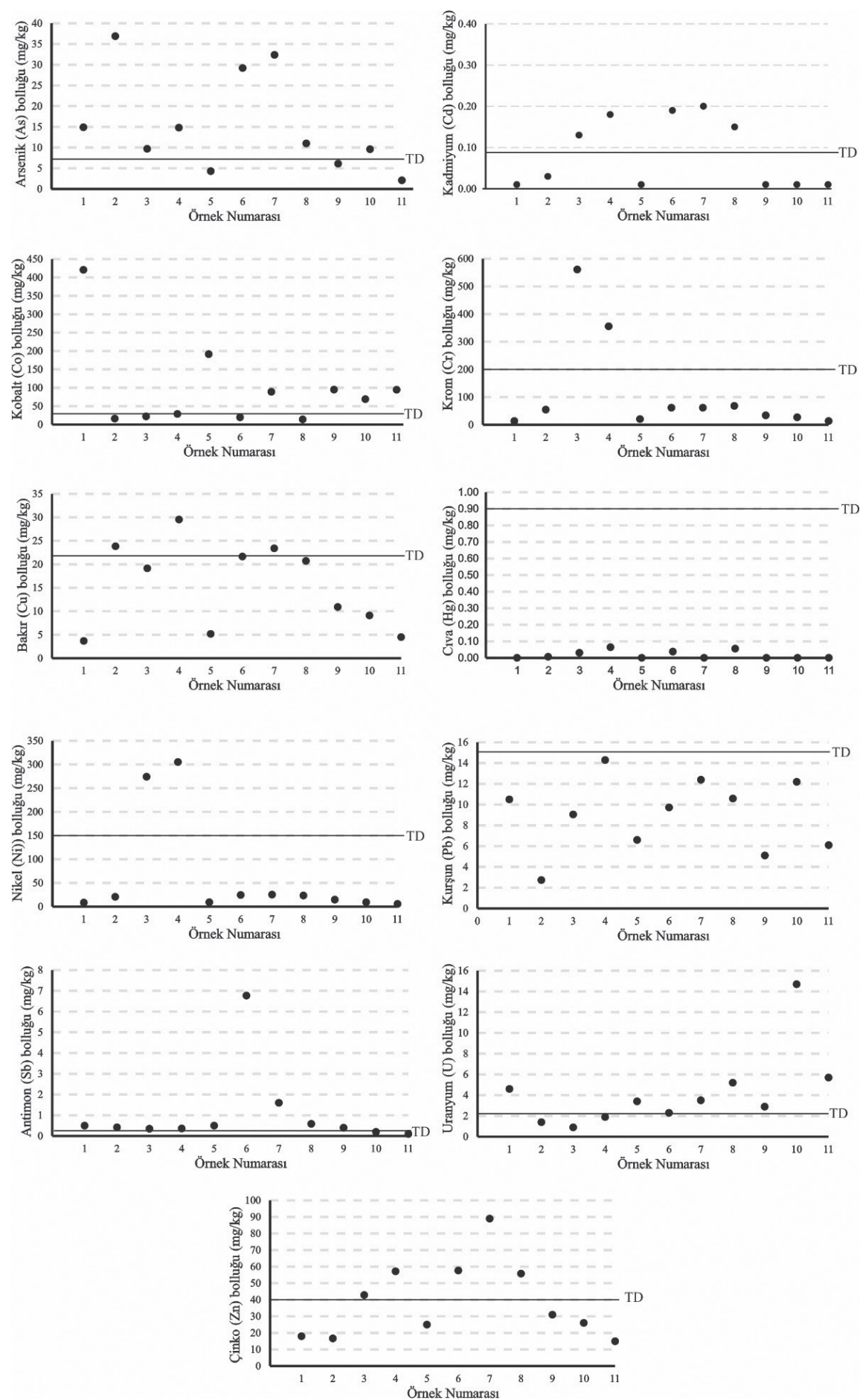

Şekil 3. Tarım topraklarının temel değer (TD) işaretli kimyasal analiz sonuçları.

Figure 3. Chemical analysis results of agricultural soils with the background value (TD) marked. 
U kirliği T5, T7 ve T8 topraklarında düşük, T1 ve T11 topraklarında kısmen, T10 toprağında ise önemli ölçüde kirlilik seviyesindedir. Yüksek düzeyde $U$ analiz edilen yeraltı suları S7 ve S12 sırasıyla T8 ve T10 toprakları ile etkileşim halindedir. Jeojenik kaynaklı gelişen kirlenme, alüvyon ile dokanağı olan bölgelerdeki yeraltı suyu ve toprakta artış göstermektedir. $\mathrm{Cu}, \mathrm{Hg}$ ve $\mathrm{Pb}$ için herhangi kirlenme söz konusu değildir. Çalışma alanında doğal seviyesindedir ve herhangi antropojenik ya da jeojenik girdi söz konusu değildir. dolayı yüksek çıkmış olması olasıdır. Yutma ve deriyle temas yoluyla Co alımı nedeniyle T3 ve T4 toprakları risklidir. İki toprakta BMN ile etkileşimdedir. As için kanserojen risk barındıran topraklar büyükten küçüğe T2, T7, T6, T1 ve T4 olarak siralanmaktadır. T2 örneği Azap Gölü'nü temsil etmektedir, yakınlarda yerleşim bulunmamaktadır. T7 toprağı Sayrakçı, T6 toprağı Nalbantlar, T1 toprağ 1 Yeşilköy, T4 toprağ 1 ise Özbaşı yerleşkelerini temsil etmektedir. Yerleşke yakınındaki tarım topraklarında As için kanserojen olan toplam sağlık riski T7,

Çizelge 8. Tarım topraklarının zenginleşme faktörü sonuçları (Jeojenik ve/veya antropojenik girdi olması muhtemel olan topraklar koyu yazılmıştır).

Table 8. Results of the enrichment factor of agricultural soils (Soils that are likely to be geogenic and/or anthropogenic inputs were marked in bold).

\begin{tabular}{cccccccccccc}
\hline & $\mathrm{As}$ & $\mathrm{Cd}$ & $\mathrm{Co}$ & $\mathrm{Cr}$ & $\mathrm{Cu}$ & $\mathrm{Hg}$ & $\mathrm{Ni}$ & $\mathrm{Pb}$ & $\mathrm{Sb}$ & $\mathrm{U}$ & $\mathrm{Zn}$ \\
$\mathrm{T} 1$ & $\mathbf{1 . 8 6}$ & $*$ & $\mathbf{1 5 . 1 5}$ & 0.06 & 0.16 & $*$ & 0.05 & 0.66 & 1.34 & $\mathbf{2 . 0 5}$ & 0.42 \\
$\mathrm{~T} 2$ & $\mathbf{6 . 0 4}$ & 0.31 & 0.77 & 0.34 & 1.33 & 0.10 & 0.17 & 0.22 & 1.47 & 0.82 & 0.51 \\
$\mathrm{~T} 3$ & $\mathbf{1 . 6 0}$ & 1.34 & 1.06 & $\mathbf{3 . 4 7}$ & 1.08 & 0.43 & $\mathbf{2 . 2 6}$ & 0.75 & 1.24 & 0.53 & 1.33 \\
$\mathrm{~T} 4$ & $\mathbf{2 . 1 6}$ & $\mathbf{1 . 6 4}$ & 1.21 & $\mathbf{1 . 9 5}$ & 1.47 & 0.79 & $\mathbf{2 . 2 3}$ & 1.04 & 1.12 & 0.99 & $\mathbf{1 . 5 6}$ \\
$\mathrm{T} 5$ & 0.62 & $*$ & $\mathbf{7 . 9 8}$ & 0.11 & 0.26 & $*$ & 0.07 & 0.48 & $\mathbf{1 . 5 5}$ & $\mathbf{1 . 7 5}$ & 0.68 \\
$\mathrm{~T} 6$ & $\mathbf{4 . 2 6}$ & $\mathbf{1 . 7 3}$ & 0.83 & 0.34 & 1.08 & 0.46 & 0.18 & 0.71 & $\mathbf{2 1 . 1 9}$ & 1.20 & $\mathbf{1 . 5 8}$ \\
$\mathrm{T} 7$ & $\mathbf{4 . 7 0}$ & $\mathbf{1 . 8 1}$ & $\mathbf{3 . 7 4}$ & 0.33 & 1.16 & $*$ & 0.18 & 0.90 & $\mathbf{4 . 9 7}$ & $\mathbf{1 . 8 1}$ & $\mathbf{2 . 4 2}$ \\
$\mathrm{T} 8$ & 1.09 & 0.93 & 0.40 & 0.25 & 0.70 & 0.46 & 0.12 & 0.53 & 1.25 & $\mathbf{1 . 8 4}$ & 1.04 \\
$\mathrm{~T} 9$ & 0.68 & $*$ & $\mathbf{3 . 0 8}$ & 0.14 & 0.42 & $*$ & 0.08 & 0.29 & 0.96 & 1.16 & 0.65 \\
$\mathrm{~T} 10$ & 1.20 & $*$ & $\mathbf{2 . 4 9}$ & 0.13 & 0.39 & $*$ & 0.06 & 0.76 & 0.53 & $\mathbf{6 . 5 5}$ & 0.61 \\
$\mathrm{~T} 11$ & 0.27 & $*$ & $\mathbf{3 . 5 1}$ & 0.07 & 0.20 & $*$ & 0.04 & 0.39 & 0.28 & $\mathbf{2 . 6 2}$ & 0.36 \\
\hline
\end{tabular}

*: Analiz limiti altında kaldığ

Maruz kalma biçimine göre (yutma, soluma, deriyle temas) toprakların kanserojen olan/ olmayan toplam sağlık riskleri; en yüksek, ortalama ve en düşük değerleriyle birlikte Çizelge 9'da listelenmiştir. Kanserojen olmayan ancak risk barındıran kirlilik parametreleri Co ve $\mathrm{Cr}$ olarak belirlenmiştir. Co ve $\mathrm{Cr}$ için yutma yoluyla meydana gelebilecek kanserojen olmayan sağlık riski en yüksek topraklar sırasıyla T1 ve T3’tür. Cr için tüm çözünmüş maddenin $\mathrm{Cr}$ (VI) olduğu varsayılmıştır. Bu varsayımdan
T6, T1 ve T4 için sırasıyla 2.38E-04, 2.14E-04, $1.21 \mathrm{E}-04$ ve $1.09 \mathrm{E}-04$ olarak hesaplanmıştır. Diğer topraklar ve analiz edilen elementler için kanserojen olan ya da olmayan sağlık riski söz konusu değildir (Çizelge 9). Kimyasal analizlerde ortalama ölçüm hatasının yüzde 10 olma durumu göz önünde bulundurularak her toprak ve elementin kanserojen olan/olmayan toplam sağlık riskleri tekrar hesaplanmıştır. Ölçüm hatasının göz ardı edildiği sonuçlar ile karşılaştırıldığında ise zararlı olarak kabul edilen 
Küçüksümbül, Tarcan

toplam kanserojen sağlik riski için $10^{-4}$ ve toplam aşan farklı bir toprak örneği tespit edilmemiştir. kanserojen olmayan sağlık riski için 1 değerini

Çizelge 9. Toprağa maruz kalma biçimine göre (yutma, soluma, deriyle temas) elementlerin kanserojen olmayan ve toplam kanser riskleri (En yüksek, ortalama ve en düşük değerler verilmiştir. Sınır değeri aşanlar koyu yazılmıştır).

Table 9. Non-carcinogenic risks of the elements by way of exposure to the soil (ingestion, inhalation and dermal) and total cancer risk (The highest, average and lowest values are given. Those exceeding the limit values are marked in bold).

\begin{tabular}{|c|c|c|c|c|c|c|c|c|}
\hline & \multicolumn{2}{|c|}{$\mathrm{RK}_{\text {oral }}$} & \multicolumn{2}{|c|}{$\mathrm{RK}_{\mathrm{sol}}$} & \multicolumn{2}{|c|}{$\mathrm{RK}_{\text {deri }}$} & \multicolumn{2}{|c|}{ Kanser Riski } \\
\hline & Çocuk & Yetişkin & Çocuk & Yetişkin & Çocuk & Yetişkin & Çocuk & Yetişkin \\
\hline \multirow{3}{*}{ As } & $5.90 \mathrm{E}-01$ & 3.37E-01 & $6.59 \mathrm{E}-04$ & $4.96 \mathrm{E}-04$ & $3.14 \mathrm{E}-02$ & $5.76 \mathrm{E}-02$ & 2.71E-04 & $1.78 E-04$ \\
\hline & $2.48 \mathrm{E}-01$ & $1.42 \mathrm{E}-01$ & $2.78 \mathrm{E}-04$ & 2.09E-04 & $7.35 \mathrm{E}-03$ & $2.43 \mathrm{E}-02$ & 1.15E-04 & $7.48 \mathrm{E}-05$ \\
\hline & $3.36 \mathrm{E}-02$ & $1.92 \mathrm{E}-02$ & $3.75 \mathrm{E}-05$ & $2.82 \mathrm{E}-05$ & $6.65 \mathrm{E}-04$ & $3.28 \mathrm{E}-03$ & $1.54 \mathrm{E}-05$ & $1.01 \mathrm{E}-05$ \\
\hline \multirow{3}{*}{$\mathrm{Cd}$} & $3.84 \mathrm{E}-03$ & $5.48 \mathrm{E}-04$ & $5.36 \mathrm{E}-06$ & $4.03 \mathrm{E}-06$ & $1.52 \mathrm{E}-03$ & $7.50 \mathrm{E}-03$ & $3.38 \mathrm{E}-10$ & $2.54 \mathrm{E}-10$ \\
\hline & $*$ & $*$ & $*$ & $*$ & $*$ & $*$ & $*$ & $*$ \\
\hline & $*$ & $*$ & $*$ & $*$ & $*$ & $*$ & $*$ & $*$ \\
\hline \multirow{3}{*}{$\mathrm{Co}$} & $1.35 E+01$ & $1.92 E+00$ & $1.88 \mathrm{E}-02$ & $1.41 \mathrm{E}-02$ & $8.88 \mathrm{E}-01$ & $6.57 \mathrm{E}-01$ & $* *$ & $* *$ \\
\hline & $3.09 E+00$ & 4.41E-01 & $4.31 \mathrm{E}-03$ & $3.24 \mathrm{E}-03$ & $2.04 \mathrm{E}-01$ & $1.51 \mathrm{E}-01$ & $* *$ & $* *$ \\
\hline & 4.47E-01 & $6.39 \mathrm{E}-02$ & $6.25 \mathrm{E}-04$ & $4.70 \mathrm{E}-04$ & $2.95 \mathrm{E}-02$ & $2.19 \mathrm{E}-02$ & $* *$ & $* *$ \\
\hline \multirow{3}{*}{$\mathrm{Cr}$} & $1.79 \mathrm{E}+00$ & $2.56 \mathrm{E}-01$ & $1.50 \mathrm{E}-03$ & $1.13 \mathrm{E}-03$ & $4.74 \mathrm{E}+00$ & $3.51 E+00$ & $9.79 \mathrm{E}-03$ & $5.64 E-03$ \\
\hline & $3.70 \mathrm{E}-01$ & $5.28 \mathrm{E}-02$ & $3.10 \mathrm{E}-04$ & $2.33 \mathrm{E}-04$ & $9.76 \mathrm{E}-01$ & $7.23 \mathrm{E}-01$ & 2.02E-03 & $1.16 \mathrm{E}-03$ \\
\hline & 4.37E-02 & $6.25 \mathrm{E}-03$ & $3.67 \mathrm{E}-05$ & $2.76 \mathrm{E}-05$ & $1.15 \mathrm{E}-01$ & $8.55 \mathrm{E}-02$ & 2.39E-04 & $1.38 \mathrm{E}-04$ \\
\hline \multirow{3}{*}{$\mathrm{Cu}$} & $9.45 \mathrm{E}-02$ & $1.35 \mathrm{E}-02$ & $* *$ & $* *$ & $4.68 \mathrm{E}-04$ & $3.46 \mathrm{E}-04$ & $* *$ & $* *$ \\
\hline & 4.89E-02 & $6.99 \mathrm{E}-03$ & $* *$ & $* *$ & $2.47 \mathrm{E}-04$ & $1.83 \mathrm{E}-04$ & $* *$ & $* *$ \\
\hline & 8.87E-04 & $1.27 \mathrm{E}-04$ & $* *$ & $* *$ & $5.85 \mathrm{E}-05$ & $4.33 \mathrm{E}-05$ & $* *$ & $* *$ \\
\hline \multirow{3}{*}{$\mathrm{Hg}$} & $3.90 \mathrm{E}-03$ & $5.57 \mathrm{E}-04$ & $5.81 \mathrm{E}-08$ & $4.36 \mathrm{E}-08$ & $2.57 \mathrm{E}-04$ & $1.90 \mathrm{E}-04$ & $* *$ & $* *$ \\
\hline & $*$ & $*$ & $*$ & $*$ & * & $*$ & $* *$ & $* *$ \\
\hline & $*$ & $*$ & $*$ & $*$ & $*$ & $*$ & $* *$ & $* *$ \\
\hline \multirow{3}{*}{$\mathrm{Ni}$} & $1.46 \mathrm{E}-01$ & $2.09 \mathrm{E}-02$ & 9.09E-04 & $6.84 \mathrm{E}-04$ & $2.42 \mathrm{E}-01$ & $1.79 \mathrm{E}-01$ & $6.87 \mathrm{E}-07$ & $5.17 \mathrm{E}-07$ \\
\hline & $3.15 \mathrm{E}-02$ & 4.49E-03 & $1.95 \mathrm{E}-04$ & $1.47 \mathrm{E}-04$ & $5.19 \mathrm{E}-02$ & $3.84 \mathrm{E}-02$ & $1.48 \mathrm{E}-07$ & $1.11 \mathrm{E}-07$ \\
\hline & $2.73 \mathrm{E}-03$ & $3.90 \mathrm{E}-04$ & $1.70 \mathrm{E}-05$ & $1.28 \mathrm{E}-05$ & $4.51 \mathrm{E}-03$ & 3.34E-03 & $1.28 \mathrm{E}-08$ & $9.65 \mathrm{E}-09$ \\
\hline \multirow{3}{*}{$\mathrm{Pb}$} & $3.92 \mathrm{E}-02$ & $5.59 \mathrm{E}-03$ & $* *$ & $* *$ & $2.58 \mathrm{E}-03$ & $1.91 \mathrm{E}-03$ & $1.24 \mathrm{E}-06$ & $2.23 \mathrm{E}-07$ \\
\hline & $2.55 \mathrm{E}-02$ & $3.65 \mathrm{E}-03$ & $* *$ & $* *$ & $1.69 \mathrm{E}-03$ & $1.25 \mathrm{E}-03$ & 7.84E-07 & $1.39 \mathrm{E}-07$ \\
\hline & $7.48 \mathrm{E}-03$ & $1.07 \mathrm{E}-03$ & $* *$ & $* *$ & 4.94E-04 & $3.65 \mathrm{E}-04$ & $2.37 \mathrm{E}-07$ & 4.27E-08 \\
\hline \multirow{3}{*}{$\mathrm{Sb}$} & $1.62 \mathrm{E}-01$ & $2.32 \mathrm{E}-02$ & $6.05 \mathrm{E}-06$ & $3.41 \mathrm{E}-05$ & $7.14 \mathrm{E}-02$ & $5.29 \mathrm{E}-02$ & $* *$ & $* *$ \\
\hline & $2.57 \mathrm{E}-02$ & $3.67 \mathrm{E}-03$ & $9.57 \mathrm{E}-07$ & $5.40 \mathrm{E}-06$ & $1.13 \mathrm{E}-02$ & 8.37E-03 & $* *$ & $* *$ \\
\hline & $2.40 \mathrm{E}-03$ & $3.42 \mathrm{E}-04$ & 8.93E-08 & $5.04 \mathrm{E}-07$ & $1.05 \mathrm{E}-03$ & 7.81E-04 & $* *$ & $* *$ \\
\hline \multirow{3}{*}{$\mathrm{U}$} & $7.05 \mathrm{E}-01$ & $1.01 \mathrm{E}-01$ & $9.85 \mathrm{E}-05$ & $7.40 \mathrm{E}-05$ & $4.65 \mathrm{E}-02$ & $3.44 \mathrm{E}-02$ & $* *$ & $* *$ \\
\hline & $2.03 \mathrm{E}-01$ & $2.90 \mathrm{E}-02$ & $2.83 \mathrm{E}-05$ & $2.13 \mathrm{E}-05$ & $1.34 \mathrm{E}-02$ & $9.90 \mathrm{E}-03$ & $* *$ & $* *$ \\
\hline & 4.32E-02 & $6.16 \mathrm{E}-03$ & $6.03 \mathrm{E}-06$ & $4.53 \mathrm{E}-06$ & $2.85 \mathrm{E}-03$ & $2.11 \mathrm{E}-03$ & $* *$ & $* *$ \\
\hline \multirow{3}{*}{$\mathrm{Zn}$} & $2.84 \mathrm{E}-03$ & $4.06 \mathrm{E}-04$ & $* *$ & $* *$ & $1.88 \mathrm{E}-04$ & $1.39 \mathrm{E}-04$ & $* *$ & $* *$ \\
\hline & $1.26 \mathrm{E}-03$ & $1.80 \mathrm{E}-04$ & $* *$ & $* *$ & $8.33 \mathrm{E}-05$ & $6.17 \mathrm{E}-05$ & $* *$ & $* *$ \\
\hline & 4.79E-04 & $6.85 \mathrm{E}-05$ & $* *$ & $* *$ & $3.16 \mathrm{E}-05$ & $2.34 \mathrm{E}-05$ & $* *$ & $* *$ \\
\hline
\end{tabular}

*: Bazı topraklardaki analiz sonuçları tayin limiti altında kaldığı için hesaplanamamıştır.

**: Referans konsantrasyon $\left(\mathrm{RfC}_{\mathrm{i}}\right.$ ) değeri veya eğim faktörü (SF) önerilmediği için hesaplanamamıştır. 


\section{Su Kirliliği}

Çalışma alanındaki yeraltı suları 225 ile 1268 $\mu \mathrm{S} / \mathrm{cm}$ arasında elektriksel iletkenlik ve 6.31 ile 8.17 arasında değişen $\mathrm{pH}$ değerlerine sahiptir. Örneklenen suların kullanım amaçları, kuyuların derinliği, bazı fiziksel parametreler ve kimyasal analiz sonuçları Çizelge 1'de verilmiştir. Avrupa Birliği (EU, 2014) ve Türk Standartlarında (TS, 2013) uranyum için herhangi eşik değer belirlenmediği için Dünya Sağlık Örgütü (WHO, 2017) ve Amerika Birleşik Devletleri Çevre Koruma Ajansı (US EPA, 2018) tarafindan uygun görülen $30 \mu \mathrm{g} / \mathrm{L}$ değeri kullanılmıştır. $\mathrm{S} 2$ ve S8 hariç tüm kaynak ve kuyu suları içme amaçlı tüketilmektedir. Suların kanserojen olan ve olmayan riskleri sadece yetişkinler için hesaplanmıştır. İçme amaçlı tüketilen sularda limit değerin üzerinde analiz edilen kirlilik parametreleri As ve U olarak öne çıkmaktadır.

Arsenik sağlık riski büyükten küçüğe sırayla $\mathrm{S} 13, \mathrm{~S} 11, \mathrm{~S} 2, \mathrm{~S} 5$ ve S1 sularında belirlenmiştir. İçme amaçlı tüketilmemesi karşın, Büyük Menderes Nehri suları As açısından toplam kanserojen riski en yüksek örneklemedir. Limit değerin 6 katından fazla arsenik içeren S11 kuyusu, Kisir bölgesinde içme amaçlı tüketilen onlarca kuyudan birisidir. Hemen hemen aynı derinlikte ve birbirine çok yakın noktalarda açılan kuyuları temsil eden örnekleme, yüksek kanserojen riski nedeniyle dikkat çekmektedir. (Çizelge 10). Sadece sudaki arsenikten kaynaklı bölge halkında 500 kişiden 1'inin kanser olması beklenir. $\mathrm{Bu}$ oran tolere edilebilecek değerin yaklaşık 20 katına karşılık gelmektedir. Karacahayıt bölgesinde yüzeye yakın kuyu sularında (S6) arsenik riski bulunmazken gnays birimine yakın ve 10 metreden yüksek sondajlar (S5) arsenik açısından risk barındırmaktadır. Yine Azap Gölü yüzey suyu örneği ve Yeşilköy kuyu suları sınır değerin üzerinde arsenik içermektedir.

Uranyum kirliliği büyükten küçüğe sırasıyla S5, S8 ve S12 sularında belirlenmiştir. S12 kaynağı gnays ile dokanağı olan bölgenin yakınında yaklaşık $1 \mathrm{~L} / \mathrm{sn}$ debiyle yüzeylenmektedir. Diğer sular ise 40 ve 45 metre derinliğindeki kuyulardan üretilmektedir. S5 ve S8 sırasıyla Karacahayıt ve Sayrakçı bölgelerini temsil etmektedir. S5 kuyu suyu limit değerin 3 katı kadar uranyum bulundurmaktadır. Bölgede kuyuların derinliği arttıkça suda çözünmüş uranyum miktarı artış göstermektedir. Söke Ovası alüvyon akiferlerinde uranyum taşınımının, potasyum ve mangan zenginleşmesiyle birlikte geliştiği belirlenmiştir (Küçüksümbül, 2018). Benzer durum çalışma alanında da geçerlidir. En yüksek çözünmüş uranyum belirlenen S5 örneği aynı zamanda en yüksek çözünmüş potasyum değerine sahiptir. Alüvyondaki örneklemelerin (S1, S3, S4, S5, S6, S7, S8, S9, S10, S11) K-U bolluk bağıntısı 0.7 olarak hesaplanmıştır. İyonların bolluğu arasındaki bağıntı, kuvvetli olarak tanımlanabilir. 
Küçüksümbül, Tarcan

Çizelge 10. Suların kanserojen ve kanserojen olmayan risk sonuçları (Tolere edilebilir değeri aşanlar koyu yazılmıştır). Table 10. Results of cancer and non-carcinogenic risk of waters (Values with higher than tolerable marked in bold).

\begin{tabular}{|c|c|c|c|c|c|c|c|c|c|c|c|c|c|}
\hline \multirow[b]{2}{*}{ Kod } & \multicolumn{10}{|c|}{ Kanserojen Olmayan Toplam Risk } & \multicolumn{3}{|c|}{ Kanserojen Toplam Risk } \\
\hline & As & B & $\mathrm{Ba}$ & $\mathrm{Cd}$ & $\mathrm{Cr}$ & $\mathrm{Cu}$ & $\mathrm{Ni}$ & $\mathrm{Pb}$ & $\mathrm{U}$ & $\mathrm{Zn}$ & As & $\mathrm{Cr}$ & $\mathrm{Pb}$ \\
\hline S1 & 1.74 & $*$ & 0.003 & * & $*$ & $*$ & 0.013 & 0.02 & 0.32 & $*$ & 7.84E-04 & $* *$ & $6.54 \mathrm{E}-07$ \\
\hline $\mathrm{S} 2^{\text {(a) }}$ & 2.09 & 0.02 & 0.005 & 0.004 & 0.005 & 0.002 & 0.004 & 0.01 & 0.36 & 0.009 & 40E-04 & $.79 \mathrm{E}-06$ & 4.23E-07 \\
\hline $\mathrm{S} 3^{(\mathrm{b})}$ & 0.05 & 0.01 & 0.004 & * & 0.003 & 0.001 & 0.017 & 0.01 & 0.97 & 0.000 & $4 \mathrm{E}-05$ & $2 \mathrm{E}-06$ & -07 \\
\hline $\mathrm{S} 4^{(\mathrm{b})}$ & 0.23 & 0.01 & 0.007 & * & 0.005 & 0.004 & 0.003 & 0.02 & 0.07 & 0.003 & 1.05E-04 & $6.79 \mathrm{E}-06$ & $5.00 \mathrm{E}-07$ \\
\hline S5 & 1.82 & 0.02 & 0.014 & .009 & 0.007 & 0.004 & 0.007 & 0.02 & 10.2 & 0.006 & 18E-04 & $1.02 \mathrm{E}-05$ & $5.00 \mathrm{E}-07$ \\
\hline S6 & $*$ & $*$ & 0.002 & $*$ & 0.035 & $*$ & $*$ & 0.01 & 0.01 & $*$ & $* *$ & $5.20 \mathrm{E}-05$ & $3.08 \mathrm{E}-07$ \\
\hline S7 & 0.48 & 0.01 & 0.002 & 0.002 & 0.003 & 0.003 & 0.002 & 0.01 & 1.36 & 0.001 & $14 E-04$ & $4.52 \mathrm{E}-06$ & $4.23 \mathrm{E}-07$ \\
\hline S8 & $*$ & $*$ & 0.010 & $*$ & $*$ & $*$ & $*$ & 0.02 & 4.07 & $*$ & $* *$ & $* *$ & $4.81 \mathrm{E}-07$ \\
\hline S9 & 0.11 & 0.004 & 0.008 & 0.004 & 0.004 & 0.004 & 0.002 & 0.01 & 2.64 & 0.007 & $5.09 \mathrm{E}-05$ & $5.66 \mathrm{E}-06$ & $4.23 \mathrm{E}-07$ \\
\hline S10 & $*$ & $*$ & 0.003 & $*$ & 0.039 & $*$ & $*$ & 0.03 & 0.41 & $*$ & $* *$ & $5.88 \mathrm{E}-05$ & $1.02 \mathrm{E}-06$ \\
\hline S11 & 4.61 & 0.00 & 0.001 & 0.003 & 0.001 & 0.001 & 0.003 & 0.01 & 1.62 & 0.001 & 2.07E-03 & $2.15 \mathrm{E}-06$ & 4.04E-07 \\
\hline S12 & 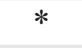 & $*$ & 0.002 & $*$ & $*$ & $*$ & 0.006 & 0.0 & 4.07 & $*$ & $* *$ & $* *$ & $3.08 \mathrm{E}-07$ \\
\hline S13 & 7.02 & 0.36 & 0.233 & 0.01 & 0.06 & 0.03 & 0.04 & 0.25 & 0.72 & 0.015 & $3.16 \mathrm{E}-03$ & $9.50 \mathrm{E}-05$ & $7.48 \mathrm{E}-06$ \\
\hline
\end{tabular}

(a): Küçüksümbül vd. 2020,

(b): Küçüksümbül vd. 2022,

*: Cihazın algılama limiti altında kalan sonuçları ifade etmektedir. İlgili laboratuvar tarafından arsenik $1 \mu \mathrm{g} / \mathrm{L}$, bor $30 \mu \mathrm{g} / \mathrm{L}$, kadmiyum $0.03 \mu \mathrm{g} / \mathrm{L}$, krom $1 \mu \mathrm{g} / \mathrm{L}$, bakır $0.5 \mu \mathrm{g} / \mathrm{L}$, çinko $30 \mu \mathrm{g} / \mathrm{L}$ olarak rapor edilmiştir.

**: Analiz limiti altında kalan değerler nedeniyle hesaplanamamıştır, suların ilgili element nedeniyle herhangi bir sağlık riski barındırmadığını ifade eder.

Çalıșma alanının hidrojeokimyasal süreçleri ve mekanizmaları belirlemek için majör iyon veri seti yorumlanmıştır. S2 Azap Gölü suyu için baskın katyon $\mathrm{Mg}$ iken, yeraltı sularının çoğunda (S3, S4, S6, S7, S8 ve S10) baskın katyon $\mathrm{Ca}$ olarak belirlenmiştir. $\mathrm{S} 1$ suyu için $\mathrm{Ca}-$ $\mathrm{Na}-\mathrm{Mg}$, S5 suyu için Ca-Mg-Na, S9 için Mg-Ca$\mathrm{Na}$ olarak belirlenmiştir. Arsenik kirliğinin en yüksek olduğu Kisir bölgesini temsil eden kuyu suyu (S11) ve uranyum kirliliğinin en yüksek olduğu S12 kaynağında ise sirasıyla baskın katyon $\mathrm{Na}-\mathrm{Mg}$ ve $\mathrm{Na}-\mathrm{Ca}$ olarak belirlenmiştir. S13 nehir suyunda ise baskin katyon $\mathrm{Mg}$ olarak bulunmuştur. Anyon analizi sorunsuzca tamamlanan (S1, S6, S8, S10 ve S12 harici) suların çoğunda (S3, S5, S7 ve S9) baskın anyon $\mathrm{HCO}_{3}$ olarak belirlenmiştir. Baskın anyonlar; S2 suyu için $\mathrm{HCO}_{3}-\mathrm{Cl}$, S4 suyu için $\mathrm{HCO}_{3}-\mathrm{SO}_{4}-\mathrm{Cl}$,
$\mathrm{S} 11$ suyu için $\mathrm{HCO}_{3}$-Cl olarak belirlenmiştir. $\mathrm{S} 13$ nehir suyu ise $\mathrm{SO}_{4}+\mathrm{HCO}_{3}$ olarak bulunmuştur. Gibbs diyagramına göre sulardan S3, S4, S7, S8, S10 kayaç baskın bölge civarında ve S1, S2, S5, $\mathrm{S} 6, \mathrm{~S} 9, \mathrm{~S} 12$ ve $\mathrm{S} 13$ ise buharlaşma etkisinin düşük ve orta düzeyde olduğu bölgede yer almaktadır (Şekil 4). Azap Gölü (S2) ve Büyük Menderes Nehri (S13) için buharlaşma etkisinden kaynaklı $\mathrm{Na}^{+}$ve $\mathrm{Cl}^{-}$zenginleşmesi beklenir.

Bölgede, arsenik ve uranyum tehlikesi gösteren sularda bu iki kirlilik parametresi arasında herhangi bağıntı belirlenememiştir. Arsenik kirliliği gnays biriminden kaynaklı olarak gerçekleşmektedir. Uranyum zenginleşmesi ise muhtemelen kuvars damarlarında meydana gelmektedir. İçme amaçlı tüketilen suların insan sağlı̆̆ını olumsuz etkileyecek niteliğe dönüşmesinde jeojenik girdiler etkendir. 


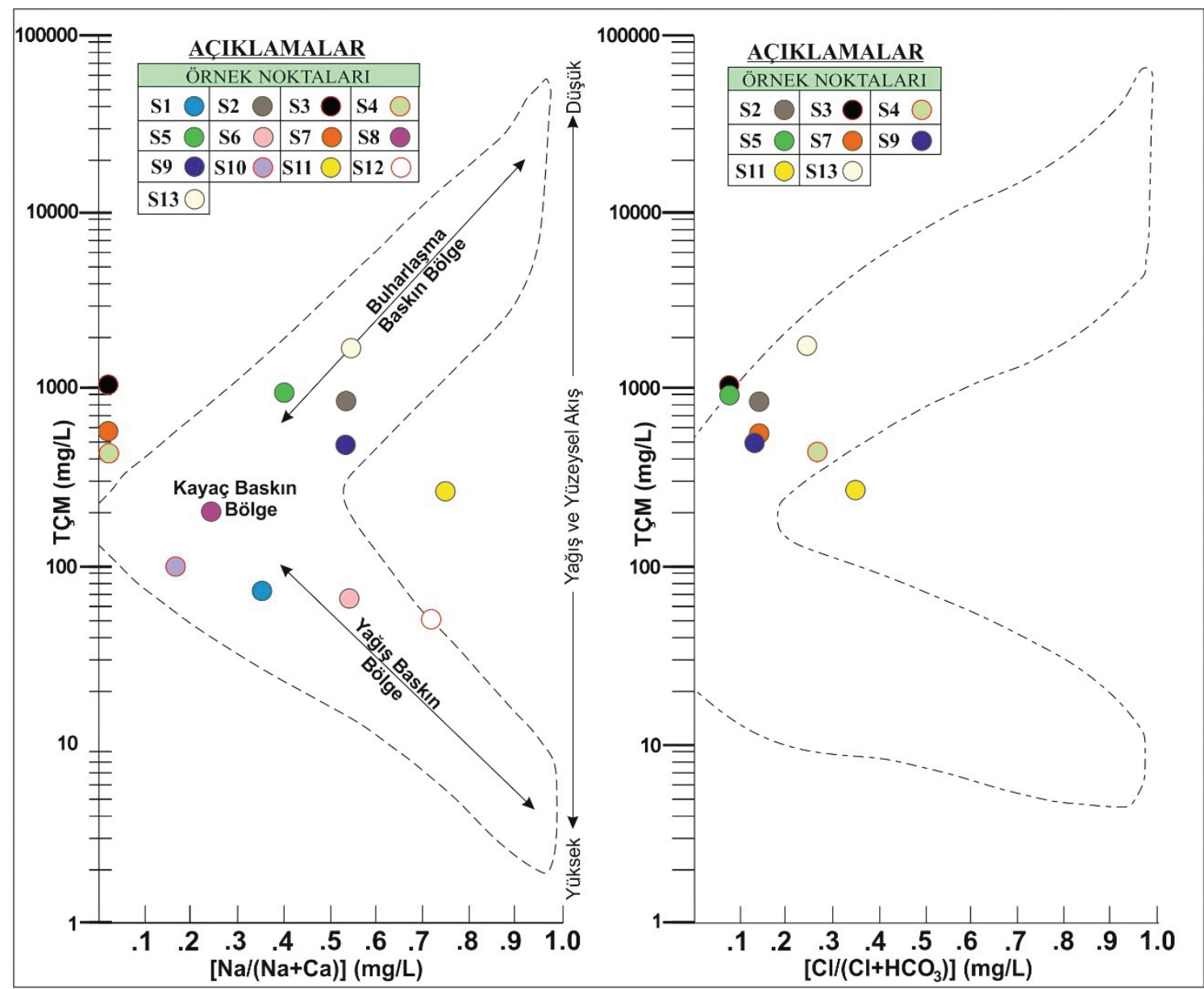

Şekil 4. Suların Gibbs (1970) diyagramında gösterimi.

Figure 4. Waters plotted in Gibbs (1970) diagram.

\section{SONUÇ VE ÖNERİLER}

Gnays biriminden kaynaklanan jeojenik girdi olarak yorumlanan topraktaki As kirlenmesi, özellikle Sayrakçı ve Nalbantlar bölge halkında kanser riski oluşturmaktadır. As nedeniyle kanserojen risk barındıran topraklar büyükten küçüğe T2, T7, T6, T1 ve T4 olarak sıralanmaktadır (Çizelge 9). Tarım topraklarında en yüksek kanser riski arsenik için 2.38E-04 olarak Sayrakçı bölgesinde belirlenmiştir. Sb zenginleşmesi bazı topraklarda çok yüksek düzeydedir. As ile birlikte $\mathrm{Sb}$ zenginleşmesi iki yar1 metalin bir arada birikimi ile açıklanabilecekken, bölgede As kirliliği görülen topraklarda Sb zenginliği T6 ve T7 toprakları hariç doğal süreç düzeyindedir. T6 ve T7 topraklarında $\mathrm{Sb}$ için antropojenik girdiden söz edilebilir. $\mathrm{Cu}$, $\mathrm{Hg}$ ve $\mathrm{Pb}$ için herhangi kirlenme söz konusu değildir. Bölge topraklarında yoğun olarak görülen Co zenginleşmesi, jeojenik girdiye bağl1 olarak gelişmiş olarak yorumlanmıştır. $\mathrm{Cr}$ ve $\mathrm{Ni}$ zenginleşmesinin nehirle sulanan topraklarda belirlenmesi, $\mathrm{Cr}$ ve $\mathrm{Ni}$ kirlenmesinin $\mathrm{BMN}$ etkisiyle geliştiğini göstermektedir. $\mathrm{Zn}$ ve $\mathrm{Cd}$ 
Küçüksümbül, Tarcan

kirliliği aynı topraklarda ve yakın seviyelerdedir. Tarımsal etkinlikten kaynaklı antropojenik girdi olarak değerlendirilmiştir. U kirliği T5, T7 ve T8 topraklarında düşük, T1 ve T11 topraklarında kısmen, T10 toprağında ise önemli ölçüde kirlilik seviyesindedir.

Yüksek düzeyde $U$ analiz edilen yeraltı sular1 S7 ve S12 sirasiyla T8 ve T10 toprakları ile etkileşim halindedir. Jeojenik kaynaklı gelişen uranyum kirlenmesi, yeraltı suyu ve toprakta bolluğa neden olmaktadır. En yüksek uranyum düzeyinin gözlendiği örneklemeler ise yüksek kotlarda gnays ile şist dokanağında hem kaynak suyunda hem de toprakta analiz edilmiştir. Karacahayıt bölgesi kuyu sularında Dünya Sağlık Örgütü (WHO) tarafından önerilen limit değerin 3 katı, Sayrakçı bölgesi kuyu sularında ise limit değerin üzerinde uranyum kirliliği tespit edilmiştir. Kuyu derinliği arttıkça sularda uranyum bolluğu artış göstermektedir. Derin dolaşımda olmayan ve düşük elektriksel iletkenliğe sahip S12 kaynağındaki yüksek uranyum, civarda uranyumca zenginleşme gösteren kayaçların olduğunu işaret etmektedir. Bölgenin uranyum potansiyeli ve jeolojisinin detaylı araştırılması gerekmektedir. Yeraltı sularında en yüksek kanser riski arsenik için 2.07E-03 olarak Kisir bölgesinde belirlenmiştir. Büyük Menderes Nehir suyu içme amaçlı tüketimde en yüksek kanser riski barındıran örneklemedir. Nehir suları yakınında içme amaçlı kuyu açılmaması önerilir. Türk Standartlarında uranyum için herhangi limit değer belirlenmemiş olup ilgili mevzuatın güncellenmesi önerilir. Bölgede açılan ya da açılması planlanan kuyuların kayıt altına alınması, sulara uranyum ve arsenik için kimyasal analizler yapıldıktan sonra kullanım izni verilmesi gerekmektedir. Sayrakçı ve Kisir bölgeleri başta olmak üzere, Karacahayıt ve Nalbantlar bölgesinde kanser vakası görülme sıklığının araştırılması ve sağlık önlemlerinin alınması önerilir.

\section{KATKI BELİRTME}

$\mathrm{Bu}$ çalışma, Dokuz Eylül Üniversitesi Rektörlüğü Bilimsel Araştırma Projeleri Koordinasyon birimi 2017.KB.FEN.014 numaralı projeden sağlanan ödenek yardımıyla gerçekleştirilmiştir. Yazarlar; Hacettepe Üniversitesi Hidrojeoloji Mühendisliği Bölümü'nden Serdar BAYARI ve Dokuz Eylül Üniversitesi Jeoloji Mühendisliği Bölümü'nden Ünsal GEMİCI'ye bilimsel değerlendirmelerinden, dergi hakemlerine makaleye önemli katkılarından ötürü teşekkür eder.

\section{KAYNAKLAR}

Akinci, G., Gök, G., Bilgin, M., 2019. Heavy metals bioconcentration and translocation in plants: the influence of a thermal power site. Environmental Engineering and Management Journal, 18(8), 1625-1637.

Bourennane, H., Douay, F., Sterckeman, T., Villanneau, E., Ciesielski, H., King, D., Baize, D., 2010. Mapping of anthropogenic trace elements inputs in agricultural topsoil from Northern France using enrichment factors. Geoderma, 157(3-4), 165-174.

CSQG (Çevre ve İnsan Sağlığının Korunması için Kanada Toprak Kalitesi Yönergeleri), 2010. Tarımsal toprak kalitesi sınır değerleri kılavuzu. http://st-ts.ccme.ca/en/index.html (14.02.2021).

Çevik, F., Göksu, M. Z. L., Derici, O. B., Fındık, Ö., 2009. An assessment of metal pollution in surface sediments of Seyhan dam by using enrichment factor, geoaccumulation index and statistical analyses. Environmental Monitoring and Assessment, 152(1), 309-317.

EU (Avrupa Birliği), 2014. Drinking Water Regulations, S.I. No. 122 of 2014.

FAO (Birleşmiş Milletler Gıda ve Tarım Örgütü), 2007. Çevre Yönetimi (Toprak Kalitesi Standartları) Düzenlemeleri. http://extwprlegs1. fao.org/docs/pdf/tan151538.pdf (14.02.2021). 
Ferreira-Baptista, L., De Miguel, E., 2005. Geochemistry and risk assessment of street dust in Luanda, Angola: a tropical urban environment. Atmospheric environment, 39(25), 4501-4512.

Gibbs, R. J., 1970. Mechanisms controlling world water chemistry. Science, 170 (3962), 10881090.

Goldschmidt, V. M., 1937. The principles of distribution of chemical elements in minerals and rocks. The seventh Hugo Müller Lecture, delivered before the Chemical Society on March 17th, 1937. Journal of the Chemical Society (Resumed), 655-673.

Güney, A., Akgül, E., 2019. Aydın'da Madencilik: Potansiyeli ve Değerlendirilmesi. TMMOB Maden Mühendisleri Odası, Ankara, 277.

Kazanc1, N., Gürbüz, A., Boyraz, S., 2011. Geology and evolution of the river Büyük Menderes, western Anatolia, Turkey. Geol. Bull. Turkey, 54, 25-56.

Küçüksümbül, A., 2018. Söke Ovası ve Bafa Gölü çevresinin hidrojeolojik incelenmesi: Jeotermal Potansiyeli, Toprak ve Su Kirliliği. Dokuz Eylül Üniversitesi Fen Bilimleri Enstitüsü. Yüksek Lisans Tezi.

Küçüksümbül, A., Akar A. T., Tarcan, G., 2020. Bafa Gölü'nün hidrokimyasal ve hidrojeolojik incelenmesi: sürdürülebilir su kaynak yönetimi. Jeoloji Mühendisliği Dergisi, 44(2), 197-224. doi.org/10.24232/jmd.826954.

Küçüksümbül, A., Akar A. T., Tarcan, G., 2022. Source, degree and potential health risk of metal(loid)s contamination on the water and soil in the Söke Basin, Western Anatolia, Turkey. Environmental Monitoring and Assessment, 194, 6. doi.org/10.1007/s10661-021-09670-2.

Lim, H. S., Lee, J. S., Chon, H. T., Sager, M., 2008. Heavy metal contamination and health risk assessment in the vicinity of the abandoned Songcheon $\mathrm{Au}-\mathrm{Ag}$ mine in Korea. Journal of Geochemical Exploration, 96(2-3), 223-230.

Luo, X. S., Ding, J., Xu, B., Wang, Y. J., Li, H. B., Yu, S., 2021. Incorporating bioaccessibility into human health risk assessments of heavy metals in urban park soils. Science of the Total Environment, 424, 88-96.

McLennan, S. M., 2001. Relationships between the trace element composition of sedimentary rocks and upper continental crust. Geochemistry, Geophysics, Geosystems, 2(4).

MEF (Finlandiya Çevre Bakanlığı), 2007. Toprak Kirliliği ve İyileştirme İhtiyaçlarının Değerlendirilmesine Dair Hükümet Karar1. https://www.finlex.fi/en/laki/kaannokset/2007/ en20070214.pdf (14.02.2021).

MTA (Maden Tektik ve Arama Genel Müdürlüğü), 2002. 1:500000 Ölçekli Aydın, Denizli, Muğla Bölgesi Jeoloji Haritası. Ankara. Türkiye.

Öztunalı, Ö., 1965. Demirtepe-Çavdar, OsmankuyuKisir (Çine Masifi) Uranyum Zuhurlarının Petrografileri ve Oluşumları. Maden Tetkik ve Arama Dergisi.

Peña-Fernández, A., González-Muñoz, M. J., Lobo-Bedmar, M. C., 2014. Establishing the importance of human health risk assessment for metals and metalloids in urban environments. Environment International, 72, 176-185.

Prasad, S., Saluja, R., Joshi, V., Garg, J. K., 2020. Heavy metal pollution in surface water of the Upper Ganga River, India: human health risk assessment. Environmental Monitoring and Assessment, 192(11), 1-15.

RAIS (Risk Değerlendirme Bilgi Sistemi), 2021a. https://rais.ornl.gov/tutorials/toxvals.html\#1 (14.02.2021).

RAIS (Risk Değerlendirme Bilgi Sistemi), 2021b. https://rais.ornl.gov/cgi-bin/tools/TOX search?select=chemtox (14.02.2021).

Rudnick, R. L., Gao, S., Holland, H. D., Turekian, K. K., 2003. Composition of the continental crust. The Crust, 3, 1-64.

Saha, N., Rahman, M. S., Ahmed, M. B., Zhou, J. L., Ngo, H. H., Guo, W., 2017. Industrial metal pollution in water and probabilistic assessment of human health risk. Journal of Environmental Management, 185, 70-78. 
Küçüksümbül, Tarcan

Sakan, S., Popović, A., Anđelković, I., Đorđević, D., 2016. Aquatic sediments pollution estimate using the metal fractionation, secondary phase enrichment factor calculation, and used statistical methods. Environmental Geochemistry and Health, 38(3), 855-867.

Shil, S., Singh, U. K., 2019. Health risk assessment and spatial variations of dissolved heavy metals and metalloids in a tropical river basin system. Ecological Indicators, 106, 105455.

Sutherland, R. A., 2000. Bed sediment-associated trace metals in an urban stream, Oahu, Hawaii. Environmental Geology, 39(6), 611-627.

TS (Türk Standardları). (2010.08.06). Toprak Kirliliğinin Kontrolü ve Noktasal Kaynaklı Kirlenmiş Sahalara Dair Yönetmelik. Resmi Gazete (27605). https://www.resmigazete.gov.tr/ eskiler/2010/06/20100608-3.htm ( 14.02.2021).

TS (Türk Standardları). (2013.03.07). İnsani Tüketim Amaçlı Sular Hakkında Yönetmelik. Resmi Gazete (28580). http://www.resmigazete.gov.tr/ eskiler/2013/03/20130307-7.htm (14.02.2021).

Turekian, K. K., Wedepohl, K. H., 1961. Distribution of the elements in some major units of the earth's crust. Geological Society of America Bulletin, 72(2), 175-192.

US EPA (Amerika Birleşik Devletleri Çevre Koruma Ajans1), 1992. Definitions and General Principles for Exposure Assessment. Guidelines for exposure assessment. Washington, DC, USA: Office of Pesticide Programs.

US EPA (Amerika Birleşik Devletleri Çevre Koruma Ajans1), 1999. Guidance for Performing Aggregate Exposure and Risk Assessments. Washington, DC, USA: Office of Pesticide Programs.
US EPA (Amerika Birleşik Devletleri Çevre Koruma Ajans1), 2004. Risk assessment guidance for superfund. Volume I: Human health evaluation manual (Part E, Supplemental Guidance for Dermal Risk Assessment). EPA/540/R/99/005. Washington, DC.

US EPA (Amerika Birleşik Devletleri Çevre Koruma Ajans1), 2018. Drinking Water Standards and Health Advisories Tables. Washington, DC, USA: Office of Water.

US EPA IRIS (Amerika Birleşik Devletleri Çevre Koruma Ajansı'nın Entegre Risk Bilgi Sistemi), 2021. https://cfpub.epa.gov/ncea/iris_drafts/ atoz.cfm (14.02.2021).

Wedepohl, K. H., 1995. The composition of the continental crust. Geochimica et Cosmochimica Acta, 59(7), 1217-1232.

WHO (Dünya Sağlık Örgütü), 2017. Guidelines for drinking-water quality. Genova, Schweiz. 1-542.

Wongsasuluk, P., Chotpantarat, S., Siriwong, W., Robson, M., 2014. Heavy metal contamination and human health risk assessment in drinking water from shallow groundwater wells in an agricultural area in Ubon Ratchathani province, Thailand. Environmental Geochemistry and Health, 36(1), 169-182.

Zhang, J., \& Liu, C. L., 2002. Riverine composition and estuarine geochemistry of particulate metals in China-weathering features, anthropogenic impact and chemical fluxes. Estuarine, Coastal and Shelf Science, 54(6), 1051-1070.

Zhao, D., Wan, S., Yu, Z., Huang, J., 2015. Distribution, enrichment and sources of heavy metals in surface sediments of Hainan Island rivers, China. Environmental Earth Sciences, 74(6), 5097-5110. 